\title{
Control of Dual-Opposed Stirling Convertors with Active Power Factor Correction Controllers
}

\author{
Timothy F. Regan ${ }^{*}$ and Edward J. Lewandowski ${ }^{\dagger}$ \\ Sest, Inc. Middleburg Heights, Ohio 44130 \\ Jeffrey G. Schreiber ${ }^{*}$ \\ NASA Glenn Research Center, Cleveland, Ohio 44135
}

\begin{abstract}
When using recently-developed active power factor correction (APFC) controllers in power systems comprised of dual-opposed free-piston Stirling convertors, a variety of configurations of the convertors and controller(s) can be considered, with configuration ultimately selected based on benefits of efficiency, reliability, and robust operation. The configuration must not only achieve stable control of the two convertors, but also synchronize and regulate motion of the pistons to minimize net dynamic forces. The NASA Glenn Research Center (GRC) System Dynamic Model (SDM) was used to study ten configurations of dual-opposed convertor systems. These configurations considered one controller with the alternators connected in series or in parallel, and two controllers with the alternators not connected (isolated). For the configurations where the alternators were not connected, several different approaches were evaluated to synchronize the two convertors. In addition, two thermodynamic configurations were considered: two convertors with isolated working spaces and convertors with a shared expansion space. Of the ten configurations studied, stable operating modes were found for four. Three of those four had a common expansion space. One stable configuration was found for the dual-opposed convertors with separate working spaces. That configuration required isochronous control of both convertors, and two APFC controllers were used to accomplish this. A frequency/phase control loop was necessary to allow each APFC controller to synchronize its associated convertor with a common frequency.
\end{abstract}

\section{Nomenclature}

$\begin{array}{ll}\text { APFC } & \text { active power factor correction } \\ \text { ASC } & =\text { Advanced Stirling Convertor } \\ \text { EMF } & =\text { electromotive force } \\ \text { GRC } & =\text { Glenn Research Center } \\ \text { SDM } & =\text { System Dynamic Model } \\ \text { SMD } & =\text { Science Mission Directorate } \\ \text { SPDE } & =\text { Space Power Demonstrator Engine } \\ \text { SSR } & =\text { subsynchronous resonance } \\ \text { TDC } & =\text { Technology Demonstration Convertor }\end{array}$

\section{Introduction}

$\mathrm{D}$ UAL-OPPOSED Stirling convertors have typically been operated with passive power factor correction using tuning capacitors. The tuning capacitors correct the power factors and operating frequencies when the two convertors are controlled by a single analog controller. This was used with the Space Power Demonstrator Engine (SPDE) that had a common expansion space shared by the two convertors, and has also been used with dual-

\footnotetext{
${ }^{*}$ Sr. Aerospace Engineer, 18000 Jefferson Park Rd, Middleburg Heights, OH 44130, AIAA Member.

${ }^{\dagger}$ Sr. Aerospace Engineer, 18000 Jefferson Park Rd, Middleburg Heights, OH 44130, AIAA Member.

* Mechanical Engineer, Thermal Energy Conversion Branch, M/S 301-2, 21000 Brookpark Rd, Cleveland, OH 44135, AIAA Member 
opposed Technology Demonstration Convertors (TDC) used for the SRG110 flight development project operating with thermodynamic cycles isolated from one another. In both cases, stable, synchronous operation was achieved.

There is a desire to use Active Power Factor Correction (APFC) controllers that eliminate the need for the tuning capacitors. ${ }^{2-5}$ The capacitors occupy volume which translates into mass in a space power generator, and impact reliability. As passive elements, they cannot be adjusted over time to account for changes in load impedance or to optimize system efficiency and performance. APFC controllers typically measure or estimate the piston position, calculate the piston velocity, and then switch various voltages at high frequency to force current to flow in proportion to the velocity. The force applied by the current appears as pure damping to the convertor if the force is in phase with the velocity. This approach minimizes electrical losses that arise from flowing current out of phase with the velocity.

APFC controllers have been developed by several labs, including GRC, and have successfully operated single Stirling convertors. Control of dual-opposed convertors with APFC control has proven to be more difficult than originally anticipated. Issues have been encountered in terms of synchronization and stability. In preparation for operating dual-opposed convertors with APFC control at GRC, a study was undertaken to determine which configurations of convertors and controllers could achieve stable, synchronous operation, and which could not.

The study investigated stability and synchronization of the various configurations. Convertors were considered stable when piston amplitude and other parameters were maintained within desired ranges. Stability was evaluated by observing the steady-state response of the system with convertors with slightly different characteristics, and also the transient response of the system to a disturbance of some form. In cases where the system was unstable, often the piston amplitude of one convertor decreased while the amplitude of the other piston grew without bound.

While it is understood that a good control system will result in stable operation, it is also a requirement that the dual-opposed convertor controller achieve synchronization of the two convertors. Synchronization is defined as both convertors operating at a common frequency with their pistons oscillating in phase with each other. By maintaining synchronization, dynamic forces generated by the internal oscillating masses are reduced.

This study used the GRC System Dynamic Model (SDM) ${ }^{6-7}$ to evaluate the candidate configurations. Two convertor models were used: the Technology Demonstration Convertor (TDC), ${ }^{8}$ manufactured by Infinia, and the Advanced Stirling Convertor (ASC), ${ }^{9}$ manufactured by Sunpower. While the study did not evaluate all possible free-piston configurations, it is felt that these results apply to many free-piston Stirling convertors when connected in the configurations studied, and are not specific to the two convertors used in this study.

The SDM simulations contain many of the nonlinearities associated with Stirling systems, including the nonlinear thermodynamics, gas dynamics, and spring rates, as well as the nonlinearities of some of the electronic components in the controller. Each simulation used an SDM model for each of the two convertors. In order to make the cases realistic, a slight difference was introduced into one of the parameters. In all the simulations performed for this study, the alternator motor constants of the two convertors differed by $0.5 \%$ to $2 \%$. External disturbances were simulated by applying a $25-\mathrm{N}$ impact on the case of one of the convertors or by varying the hot-end or cold-end temperature of one of the convertors by $2^{\circ} \mathrm{C}$. The hardware realization of two Stirling convertors will not be exact copies one another. The differences must be dealt with in the system design. SDM used the slightly different motor constants to mimic the hardware case and present a realistically dissimilar pair to the APFC controller.

\section{A. Related work}

The interconnection and operation of multiple free-piston Stirling convertors was studied by White in $1999 .{ }^{10}$ The study investigated means of synchronizing convertors operating with tuning capacitors and with an analog controller. Various dual-opposed configurations were simulated with a linear model and the results were compared with test data. All of these configurations included tuning capacitors and had either one or two Zener diode controllers with the alternators connected electrically in parallel either before or after the tuning capacitors or after the controllers. Series connection of the alternators was not considered.

Both the simulation studies and the test data included not only steady-state data but also data describing transient responses due to making and breaking the parallel electrical connection between the two alternators. Operation with significant amounts of unbalance in the convertor fill pressures and in operating temperatures was studied and the effects described in the report. Each configuration was studied with the convertor cases rigidly connected to each other as well as with convertor cases mechanically isolated. With isolated cases, the mechanical connection to transmit dynamic forces was broken.

The report identified the two-convertor/one-controller system with alternators connected in parallel after tuning capacitors as a robust, stable configuration. This configuration has been used for a significant amount of testing at GRC. 
Another contribution to the body of knowledge related to control of multiple free-piston convertor systems came from the SPDE project in which two $12.5 \mathrm{~kW}$ convertors were coupled through a common expansion space as well as through the alternator electrical connections. The alternators and electrical load were connected in series with the system's two linear alternators through a tuning capacitor located after the two alternators. Testing showed that the SPDE operated stably under a wide range of operating conditions.

In addition, there is nearly 100 years' worth of engineering literature describing the development of interconnected power systems. Among the concepts potentially relevant to the dual-opposed convertor control problem is the phenomenon of subsynchronous resonance (SSR). SSR is an electric power system condition where the electric network exchanges energy with a generator at a natural frequency of the combined system below the synchronous frequency of the system. ${ }^{11}$ Methods of analyzing and eliminating the effects of subsynchronous resonance in interconnected power systems have been discussed in the literature in relation to large 3-phase rotating systems, but the concepts have been found useful in studying dual-opposed Stirling control systems. The significant contribution from the literature concerns the manipulation of generator frequency to control SSR.

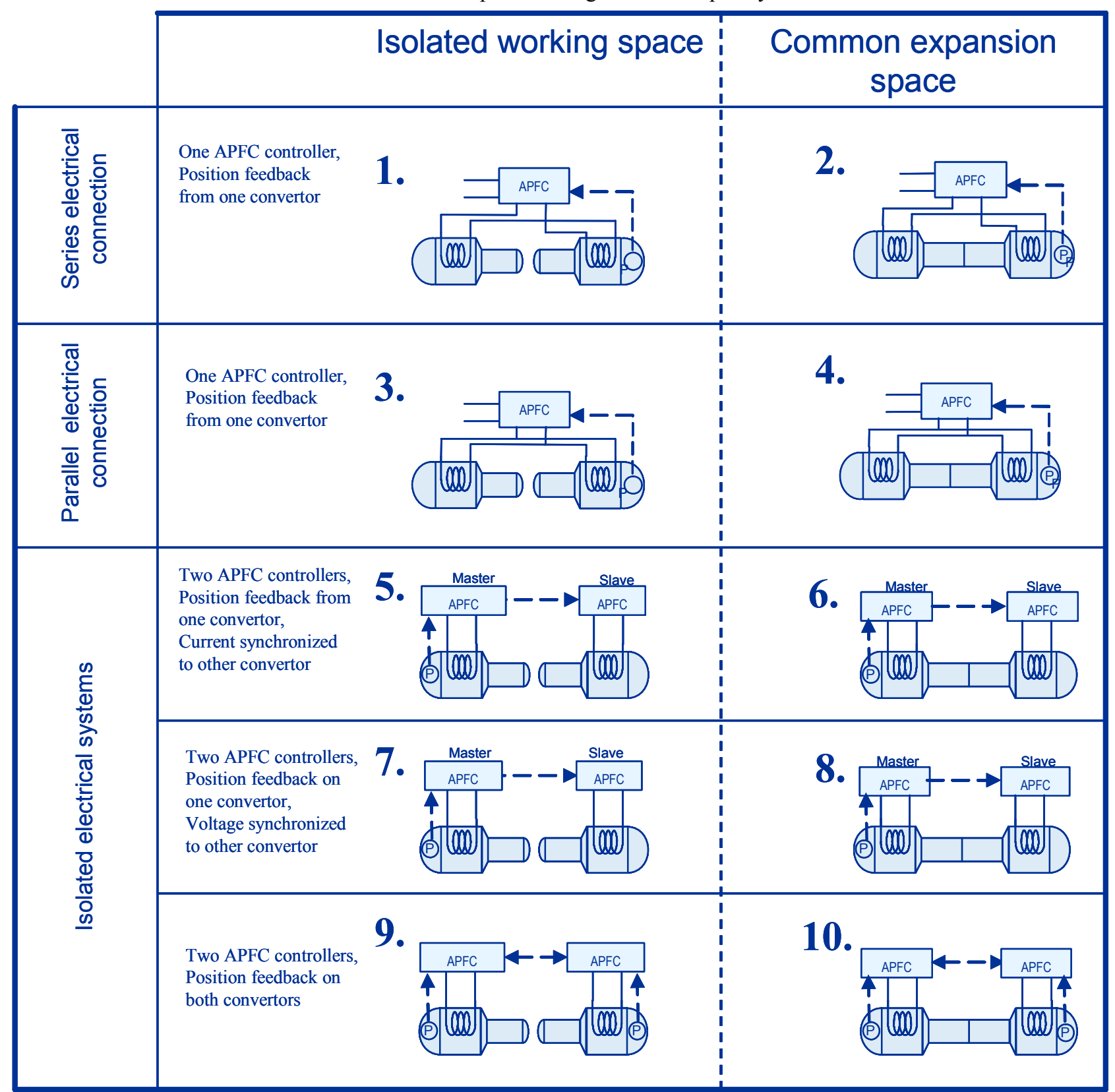

Figure 1. Ten candidate configurations of dual-opposed convertors with APFC controllers. 


\section{Configurations of dual-opposed convertors with APFC controllers}

Ten configurations of convertors and controllers were identified for this study. These ten configurations are shown in Fig. 1. They use parallel or series electrical connection of the linear alternators, shared or isolated thermodynamic cycles, and single or dual APFC controllers. The first four have a single APFC controller and the last six have two controllers.

All configurations had the cases of the two convertors rigidly connected, so that the cases of the two convertors act dynamically as one in the range of the operating frequency. The rigid case connection provides a direct path for the opposing dynamic forces of the two convertors. The amplitude of the case is generally small and can be influenced by the mounting dynamics between the case and the external system. Stability of the system can be influenced in situations where case amplitude increases significantly. In all configurations simulated the convertor case was connected to ground via a reasonably stiff spring and damper.

\section{A. Thermodynamic configurations}

Isolated working space.

It is common to configure two convertors with isolated working spaces, meaning that neither the expansion space nor compression space is shared between the two convertors.

Common expansion space.

In the common expansion space configuration, the working spaces of the two convertors are connected. This configuration has the rigid case connection discussed previously. Both convertors see the same pressure wave acting on the power pistons, providing a strong coupling between the two convertors. The SPDE is an example of dual-opposed convertors connected with a common expansion space. ${ }^{12}$ This configuration is shown schematically in Fig. 2.

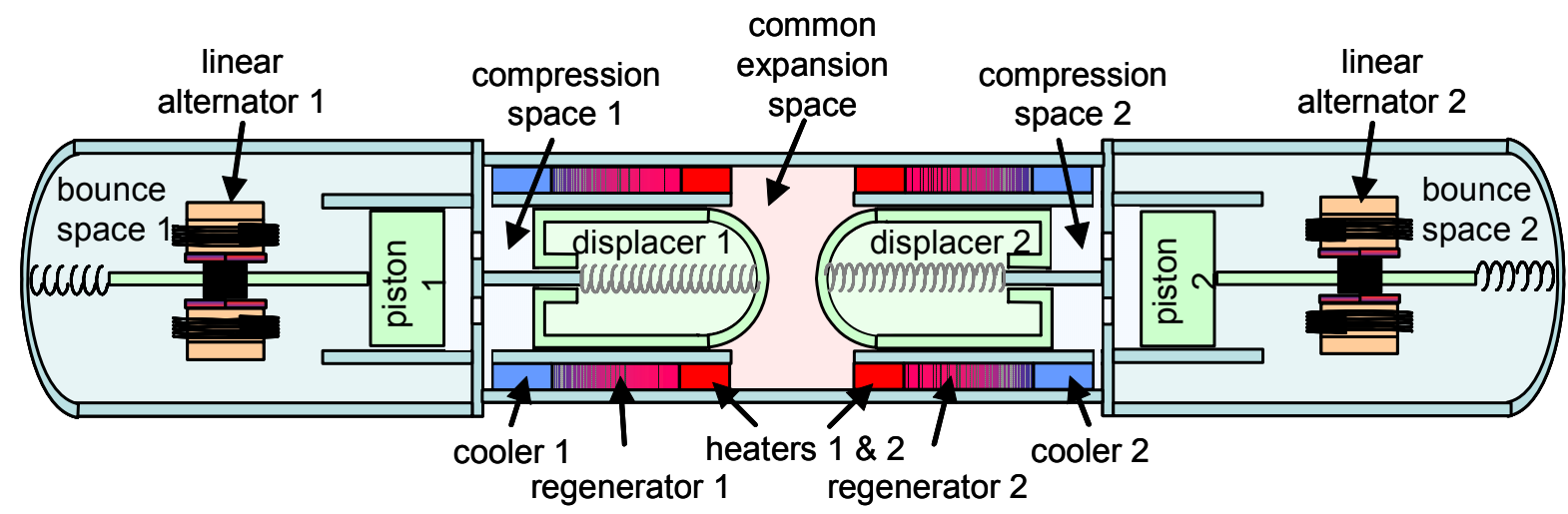

Figure 2. Cross-section schematic of dual-opposed convertors with a common expansion space.

\section{B. Electrical configurations}

\section{Series electrical connection}

With the series electrical connection of the linear alternators, the same current flows through each alternator. The APFC controller for this configuration commands a single current to the series alternators based on feedback from one or both of the convertors' piston position signals. With a single controller, it is not possible to independently control the voltage to each convertor.

\section{Parallel electrical connection}

With the parallel electrical connection, both alternators see the same voltage, but may have different currents. In this case, it is not possible to independently control the current to each convertor.

3. Isolated electrical systems

Electrically isolated convertors were considered where the only connection between the alternators was through two APFC controllers, and there is no direct electrical connection. The controllers must act in such a way so as to maintain synchronization of the two convertors. There are three ways considered in which to maintain synchronization: 1) current synchronization, 2) voltage synchronization, and 3) position feedback on both convertors. 
Configurations \#5 through \#8 attempted to achieve synchronization by synthesizing the effect of either serieswired or parallel-wired operation of the second convertor. The electrically isolated configurations require two active bridge circuits; one for each convertor. The current-synchronized configurations and the voltage-synchronized configurations require only one set of control electronics for the two active bridges. In these configurations, the current or voltage calculated by the control circuitry was based on the master convertor's performance and piston position feedback and was used by both active bridges to control both convertors.

Configurations \#9 and \#10 sense piston position on both convertors. This allows independent control of each convertor based on the separate feedback.

\section{Simulation of configurations}

GRC's Stirling convertor SDM was used to simulate the ten configurations. The simulations began with convertors going through start up to full power operation. If the simulations reached steady-state operation stably and synchronized, a $25-\mathrm{N}$ impulse force was applied to the convertor case to determine robustness of the system in response to an outside disturbance.

\section{A. Convertor Model}

The Stirling convertor models used in this study included the TDC manufactured by Infinia and the ASC manufactured by Sunpower. These models included the essential dynamics of the convertor, including Stirling cycle thermodynamics; heat flow; gas, mechanical, and mounting dynamics. The SDM includes nonlinearities and subcycle dynamics. The linear alternator was modeled as a voltage source in series with an inductor and resistor.

The common expansion space convertor model used in this study was based on the layout of the SPDE, although the model parameters were based on the TDC. The following assumptions were made:

- Expansion space volume was twice that of a single TDC's expansion space volume

- Heater temperature $T_{h}$ was identical for both convertors

- Working fluid was shared between the two convertors. Temperatures in the various convertor volumes determined actual distribution of the working fluid.

\section{B. APFC Controller Model}

The APFC controller model used in this study was a simplified representation of an APFC controller. It did not include actual power electronic components and was not based on an exact APFC controller circuit design. While it would be more accurate to use a detailed APFC controller design for the analysis, the simplified controller was used to reduce computation time. Use of the simplified controller should not influence the conclusions of the study.

The model of the APFC controller used in SDM for this study consisted of a switching/energy storage module that switches positive and negative voltages onto the alternator leads to force the alternator current to a predetermined value. The predetermined value was based on a reference current that was a synthesized sine wave whose amplitude was determined by a control loop designed to maintain a set point of piston amplitude. The amplitude of the current was determined in this study by a control loop to keep piston amplitude at its set point value. If the piston amplitude was greater than the set point, the control loop raised the current amplitude to increase the load and bring the piston amplitude back to its set point. If the piston amplitude was less than the set point, the control loop decreased the current amplitude.

Specification of the phase angle of the reference current was the means whereby the power factor was controlled. To correct the power factor to unity, a phase angle of zero degrees between the current and the velocity was chosen. With a phase angle of zero degrees, the reference current was synthesized to be in phase with the generated electromotive force (EMF). The EMF cannot be measured, but it is known to be in phase with the velocity of the alternator and thus in phase with the piston velocity. The controller model managed the phase relationships by observing the times at which the piston position achieved a cycle minimum and identifying that time as the positive zero-crossing time of piston velocity, designated as $T_{0}$. The phase angle of the reference current was adjusted each cycle. The reference current synthesizer used in the model was also able to synthesize non-zero phase angles. Such phase angles yield non-unity power factors. In such cases, the reference current was timeshifted from the piston velocity; the current led or lagged the alternator EMF by a known value.

The frequency used by the reference current synthesizer was also determined from observations of the zero crossings of piston position. The reference current frequency was corrected once per cycle. 


\section{Results of the Study}

Table II summarizes the ten dual-opposed convertor-APFC controller configurations analyzed using SDM and identifies which configurations resulted in stable operation. Configurations 2, 4, 9, and 10 showed stable operation while the other six were not found to be stable. In the cases of unstable operation, the piston amplitudes diverged from the nominal equal value with the amplitude of one convertor decreasing and the amplitude of the other convertor growing. The piston amplitude that grew appeared to grow without bound until the physical limits of the hardware were reached. After the piston amplitudes diverged, there did not appear to be any tendency for the piston amplitudes to come back in range.

Three of the four stable configurations were convertors with a common expansion space, while there was only one stable configuration with isolated working spaces. Comparing configurations \#1 and \#3 versus configurations $\# 2$ and \#4, the only difference is that the former have isolated working spaces, while the latter have a common expansion space. This suggests that the stabilizing and synchronizing effect of the common expansion space was significant. With a common expansion space, both convertors essentially see the same pressure wave. The same pressure wave acts on both pistons, largely independent of differences in convertor parameters, which tends to synchronize their motions. A similar stabilizing effect is expected with convertors with a common compression space, but that was not simulated.

The stable configuration with isolated working spaces requires two controllers and two position sensors with the slave side of the system essentially being directed to mimic the piston position of the master side of the system. This configuration is more complex in that it requires two APFC controllers and two position sensors.

Table II. Summary of simulation results.

\begin{tabular}{|c|c|c|c|c|}
\hline $\begin{array}{c}\text { Configuration } \\
\text { no. }\end{array}$ & $\begin{array}{l}\text { Thermodynamic } \\
\text { configuration }\end{array}$ & $\begin{array}{c}\text { Electrical } \\
\text { configuration }\end{array}$ & Controller & $\begin{array}{c}\text { Simulation } \\
\text { results }\end{array}$ \\
\hline 1 & $\begin{array}{l}\text { Isolated working } \\
\text { space }\end{array}$ & \multirow{2}{*}{$\begin{array}{l}\text { Series electrical } \\
\text { connection }\end{array}$} & \multirow{2}{*}{$\begin{array}{l}\text { One APFC controller, position } \\
\text { feedback from one convertor }\end{array}$} & Unstable \\
\hline 2 & $\begin{array}{c}\text { Common expansion } \\
\text { space }\end{array}$ & & & Stable \\
\hline 3 & $\begin{array}{l}\text { Isolated working } \\
\text { space }\end{array}$ & \multirow{2}{*}{$\begin{array}{l}\text { Parallel } \\
\text { electrical } \\
\text { connection }\end{array}$} & \multirow{2}{*}{$\begin{array}{l}\text { One APFC controller, position } \\
\text { feedback from one convertor }\end{array}$} & Unstable \\
\hline 4 & $\begin{array}{c}\text { Common expansion } \\
\text { space }\end{array}$ & & & Stable \\
\hline 5 & $\begin{array}{c}\text { Isolated working } \\
\text { space }\end{array}$ & \multirow{6}{*}{$\begin{array}{l}\text { Isolated } \\
\text { electrical } \\
\text { systems }\end{array}$} & \multirow{2}{*}{$\begin{array}{l}\text { Two APFC controllers, position } \\
\text { feedback from one convertor, } \\
\text { current synchronized to other } \\
\text { convertor }\end{array}$} & Unstable \\
\hline 6 & $\begin{array}{l}\text { Common expansion } \\
\text { space }\end{array}$ & & & Unstable \\
\hline 7 & $\begin{array}{l}\text { Isolated working } \\
\text { space }\end{array}$ & & \multirow{2}{*}{$\begin{array}{l}\text { Two APFC controllers, position } \\
\text { feedback from one convertor, } \\
\text { voltage synchronized to other } \\
\text { convertor }\end{array}$} & Unstable \\
\hline 8 & $\begin{array}{l}\text { Common expansion } \\
\text { space }\end{array}$ & & & Unstable \\
\hline 9 & $\begin{array}{l}\text { Isolated working } \\
\text { space }\end{array}$ & & \multirow{2}{*}{$\begin{array}{l}\text { Two APFC controllers, position } \\
\text { feedback on both convertors }\end{array}$} & Stable \\
\hline 10 & $\begin{array}{l}\text { Common expansion } \\
\text { space }\end{array}$ & & & Stable \\
\hline
\end{tabular}

\section{A. Configurations \#1 and \#2 with series electrical connection}

The SPDE system was configured with the two alternators wired in series, along with a passive controller and tuning capacitor. This may have fostered a notion that series wiring is a viable configuration to consider for other free-piston convertors where the tuning capacitor and passive controller are replaced by an APFC controller. However, SDM simulations suggest that an APFC controller and alternators connected in series will not stabilize convertors with isolated working spaces (configuration \#1). Convertors with common expansion space like the SPDE appear stable when connected in series with an APFC controller (configuration \#2).

\section{B. Configurations \#3 and \#4 with parallel electrical connection}

As mentioned earlier, many dual-opposed convertor systems are currently tested at GRC connected in parallel with tuning capacitors and passive controllers. Simulations of configuration \#3 showed that convertors with isolated 
working spaces were unstable when connected in parallel with an APFC controller. The similar results have been observed in the test cell when operation was attempted without tuning capacitors.

When tuning capacitors are removed from the parallel circuit, it appears that the current to the two convertors is split in such a way that it tends to destabilize the system instead of stabilizing the system. With real hardware one alternator's EMF will be slightly larger than the other's EMF because no two convertors can be perfectly matched. With the alternators directly connected to the controller in parallel, the larger portion of the total current goes to the
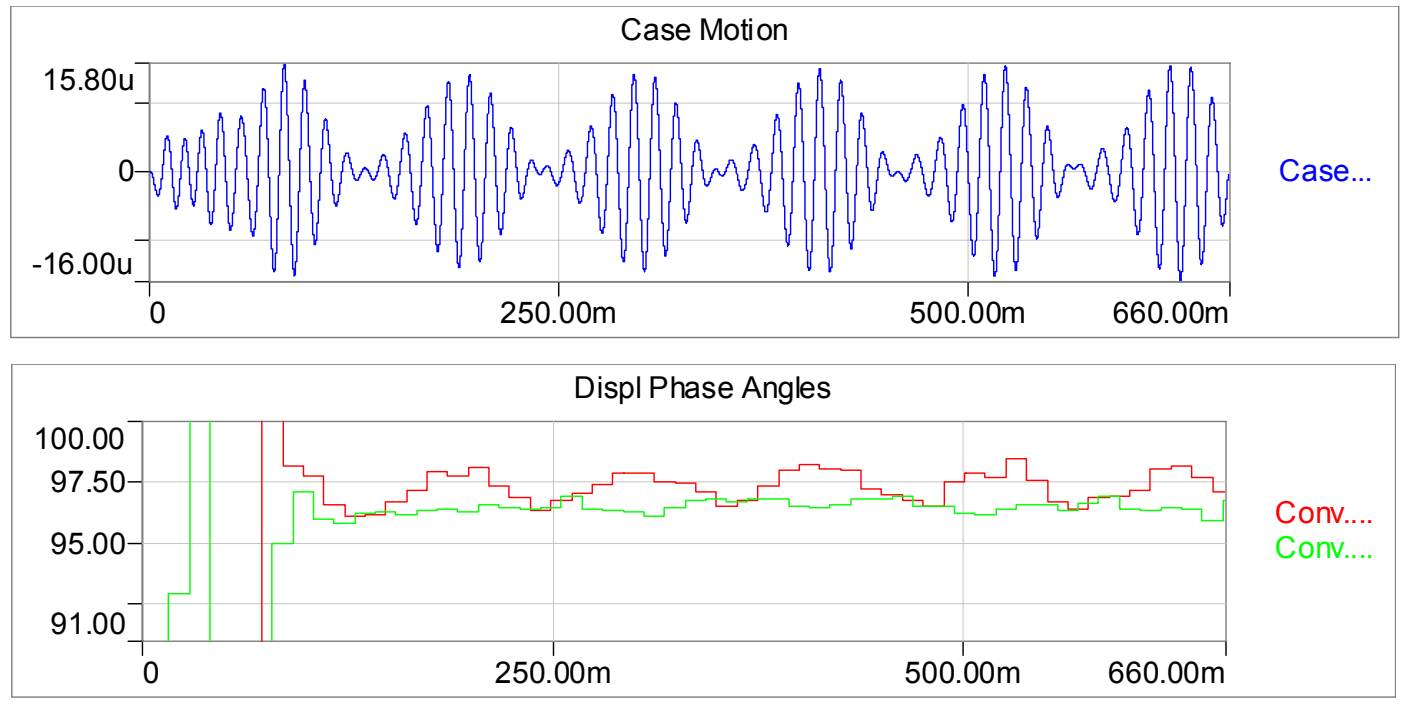

Figure 3. Case motion and displacer phase angles from a simulation of Configuration \#4. Single APFC controller parallel connected common expansion space convertors.

alternator with the smaller voltage. The higher current tends to apply more damping to that alternator, which further reduces that convertor piston's amplitude. That in turn reduces the alternator's EMF, making subsequent amplitudes even smaller. The alternator with the larger amplitude sees less damping, allowing its amplitude to grow. This is theorized to be the cause of instability observed in some of the parallel configurations studied.

Configuration \#4 was the same as configuration \#3, but with a common expansion space. This configuration was found to be stable. In some simulations a small limit cycle was observed, as shown in Fig. 3. Further investigation is needed to understand the source of the limit cycle and identify methods to eliminate it.

\section{Configurations \#5 through \#10 with electrically isolated alternators}

Simulations of the configurations with electrically isolated alternators (configurations \#5 through \#10) identified only configurations $\# 9$ and $\# 10$ as being stable.

Current-synchronized electrically-isolated configurations $\# 5$ and $\# 6$ essentially mimic series-wired configurations \#1 and \#2, since the alternators arranged in current-synchronized configurations see a similar current as if they were actually wired in series. No stable mode was found in simulation with either the common expansion space configuration $\# 5$ or the isolated working space configuration $\# 6$, even though configuration $\# 2$ was found to be stable. Further investigation is needed to understand why configuration \#6 was unstable, and if there are cases for which it might be stable.

Figure 4 is a typical case position versus time plot of a simulation of configuration $\# 5$. Typically in the simulations one of the piston amplitudes was unable to be controlled and the piston hit the end stop, indicating instability. 


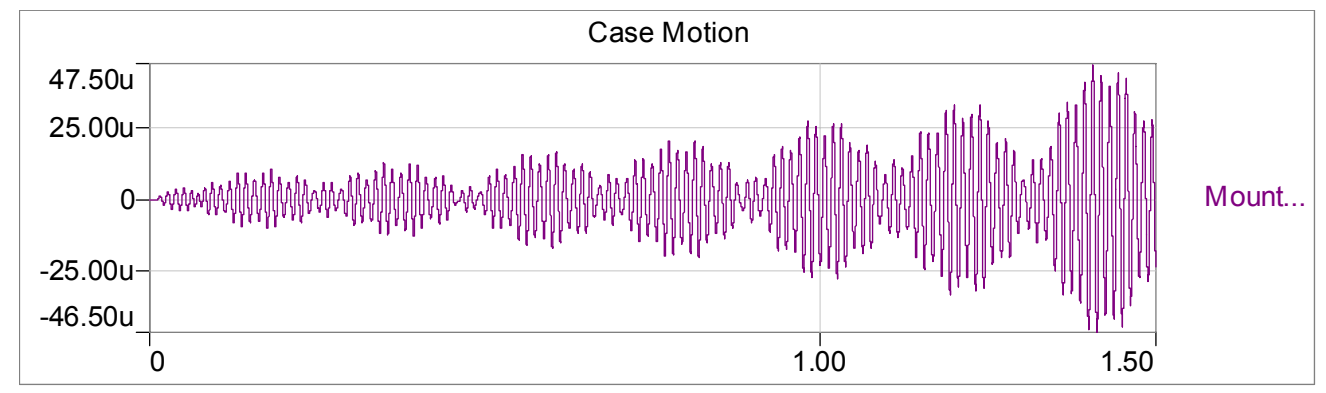

Figure 4. Increasing case motion from Configuration \#5, indicating system instability.

The case motion shown in Fig. 4 did play a role in how fast the system became unstable and when the piston of one convertor hit the end stop. Depending on how the convertors were mismatched and whether the natural frequency of the mounting system was above or below the convertor operating frequency, the case motion would either provide positive feedback or negative feedback to the convertor with the increasing piston amplitude. Regardless of the nature of the feedback, the system was still unstable, as the case motion plays only a small role in the system dynamics.

Voltage-synchronized electrically-isolated configurations \#7 and \#8 are similar to the parallel-connected configurations \#3 and \#4. As with configuration \#3, configuration \#7 was also found to be unstable. Configuration \#8 was also unstable, although configuration \#4 was stable. Further investigation is recommended here.

Stable modes were found for configurations $\# 9$ and \#10. In these configurations, the two active bridges were controlled independently. Feedback of piston position from both convertors allowed the controllers to determine the current phase relative to piston velocity for each convertor, as well as the relative piston phasing between the two convertors. By independently adjusting the current phasing to each convertor, the desired piston phasing and amplitude can be achieved, resulting in stable and synchronized operation of the dual-opposed convertors.

The APFC controllers can provide more flexibility than tuning capacitors to account for changes in load impedance over time or to optimize system efficiency and performance based on various criteria such as power, efficiency, or vibration. These options are being developed at GRC.

\section{Conclusions}

The stability of ten configurations of dual-opposed Stirling convertors controlled by APFC controllers was studied through dynamic simulation. Different thermodynamic, electrical, and controller configurations were studied. Four configurations were found to stabilize and synchronize the two convertors.

Of the five configurations with isolated working spaces, only one configuration was stable, configuration \#9, with isolated electrical systems, two APFC controllers, and position feedback from both convertors. Configurations that relied on position feedback from just one convertor or connected the convertors electrically in series or in parallel were not able to be stabilized.

Three of the configurations with a common expansion space were stable. This suggests that the stabilizing and synchronizing effect of the common expansion space is significant. A similar stabilizing effect is expected with convertors with a common compression space. Further investigation is recommended to understand why stable modes were not identified for the other two configurations with a common expansion space and to determine if stable modes for these configurations do exist. Analysis has shown that operation can be affected to influence power, efficiency, or vibration. Many control algorithms have been tested analytically with SDM to find the simplest and most robust control strategies.

\section{Acknowledgments}

This work was performed for NASA Headquarters, Science Mission Directorate (SMD) under the Radioisotope Power Systems (RPS) Program and was supported by the NASA Glenn Research Center Contract NAS3-03064. Any opinions, findings, and conclusions or recommendations expressed in this article are those of the authors and do not necessarily reflect the views of the National Aeronautics and Space Administration. 


\section{References}

${ }^{1}$ Brown, A. T., "Space Power Demonstrator Engine", Phase I Final Report, Mechanical Technology, Inc., Latham NY, NASA Contractor Report 179555, May 1987.

${ }^{2}$ Gerber, S.S., Jamison, M., Regan, T.F., and Roth, M.E., "Advanced Controller for the Free-Piston Stirling Convertor," Proceedings of the Second International Energy Conversion Engineering Conference (IECEC 2004), AIAA, Providence, RI, 2004.

${ }^{3}$ Daboussi, Z., “An Inverter-Based Sensorless Controller for Free-Piston Stirling Engines," Proceedings of the $35^{\text {th }}$ Annual IEEE Power Electronics Specialists Conference, Aachen, Germany, 2004, pp. 1707-1710.

${ }^{4}$ Lynch, T.H. and Koch, B., "Thermal Cycle Engine Boost Bridge Power Interface,” U.S. Patent 6,871,495, Mar. $29,2005$.

${ }^{5}$ Holliday, E. and Keiter, D.E., "Control Electronics for Palm Power 35W Free-Piston Stirling Engine," Proceedings of the Third International Energy Conversion Engineering Conference (IECEC 2005), AIAA, San Francisco, CA, 2005.

${ }^{6}$ Lewandowski, E.J. and Regan, T.F., "Overview of the GRC Stirling Convertor System Dynamic Model," Proceedings of the Second International Energy Conversion Engineering Conference (IECEC 2004) AIAA, Providence, RI, 2004.

${ }^{7}$ Regan, T.F., Lewandowski, E.J., "Application of the GRC Stirling Convertor System Dynamic Model," Proceedings of the Second International Energy Conversion Engineering Conference (IECEC 2004) AIAA, Providence, RI, 2004.

${ }^{8}$ Qiu, S., Augenblick, J.E., White, M.A., Peterson, A.A., Redinger, D.L. and Peterson, S.L., Developing a Free-Piston Stirling Convertor for Advanced Radioisotope Space Power Systems," in Proceedings of the Space Technology and Applications International Forum, (STAIF 2002), American Physical Society.

${ }^{9}$ Wood, J.G., Carroll, C., Matejczyk, D., and Penswick, L.B., “Advanced $80 \mathrm{~W}_{\mathrm{e}}$ Stirling Convertor Phase II Development Progress," Proceedings of the Third International Energy Conversion Engineering Conference (IECEC 2005), AIAA, San Francisco, CA, 2005.

${ }^{10}$ White, M. A. and Qiu, S., "Innovative Integration of Long-Life High Efficiency Thermal Convertors Using Proven FreePiston Stirling Machines", SBIR Phase II Final Technical Report, Stirling Technology Co. (currently known as Infinia Corp.) Kennewick, WA, 1999.

${ }^{11}$ IEEE SSR Working Group, "Proposed Terms and Definitions for Subsynchronous Resonance," IEEE Symposium on Countermeasures for Subsynchronous Resonance, IEEE Pub. 81TH0086-9-PWR, 1981, pp. 92-97.

${ }^{12}$ Dochat, G.R., "Free piston space Stirling technology program," Proceedings of the 24th Intersociety Energy Conversion Engineering Conference (IECEC-89) IEEE, Washington, DC, Aug 6-11, 1989. 


\title{
Control of Dual-Opposed Stirling Convertors with Active Power Factor Correction Controllers
}

\author{
Timothy F. Regan ${ }^{*}$ and Edward J. Lewandowski ${ }^{\dagger}$ \\ Sest, Inc. Middleburg Heights, Ohio 44130 \\ Jeffrey G. Schreiber \\ NASA Glenn Research Center, Cleveland, Ohio 44135
}

\begin{abstract}
When using recently-developed active power factor correction (APFC) controllers in power systems comprised of dual-opposed free-piston Stirling convertors, a variety of configurations of the convertors and controller(s) can be considered, with configuration ultimately selected based on benefits of efficiency, reliability, and robust operation. The configuration must not only achieve stable control of the two convertors, but also synchronize and regulate motion of the pistons to minimize net dynamic forces. The NASA Glenn Research Center (GRC) System Dynamic Model (SDM) was used to study ten configurations of dual-opposed convertor systems. These configurations considered one controller with the alternators connected in series or in parallel, and two controllers with the alternators not connected (isolated). For the configurations where the alternators were not connected, several different approaches were evaluated to synchronize the two convertors. In addition, two thermodynamic configurations were considered: two convertors with isolated working spaces and convertors with a shared expansion space. Of the ten configurations studied, stable operating modes were found for four. Three of those four had a common expansion space. One stable configuration was found for the dual-opposed convertors with separate working spaces. That configuration required isochronous control of both convertors, and two APFC controllers were used to accomplish this. A frequency/phase control loop was necessary to allow each APFC controller to synchronize its associated convertor with a common frequency.
\end{abstract}

${ }^{*}$ Sr. Aerospace Engineer, 18000 Jefferson Park Rd, Middleburg Heights, OH 44130, AIAA Member.

${ }^{\dagger}$ Sr. Aerospace Engineer, 18000 Jefferson Park Rd, Middleburg Heights, OH 44130, AIAA Member.

* Mechanical Engineer, Thermal Energy Conversion Branch, M/S 301-2, 21000 Brookpark Rd, Cleveland, OH 44135, AIAA Member 

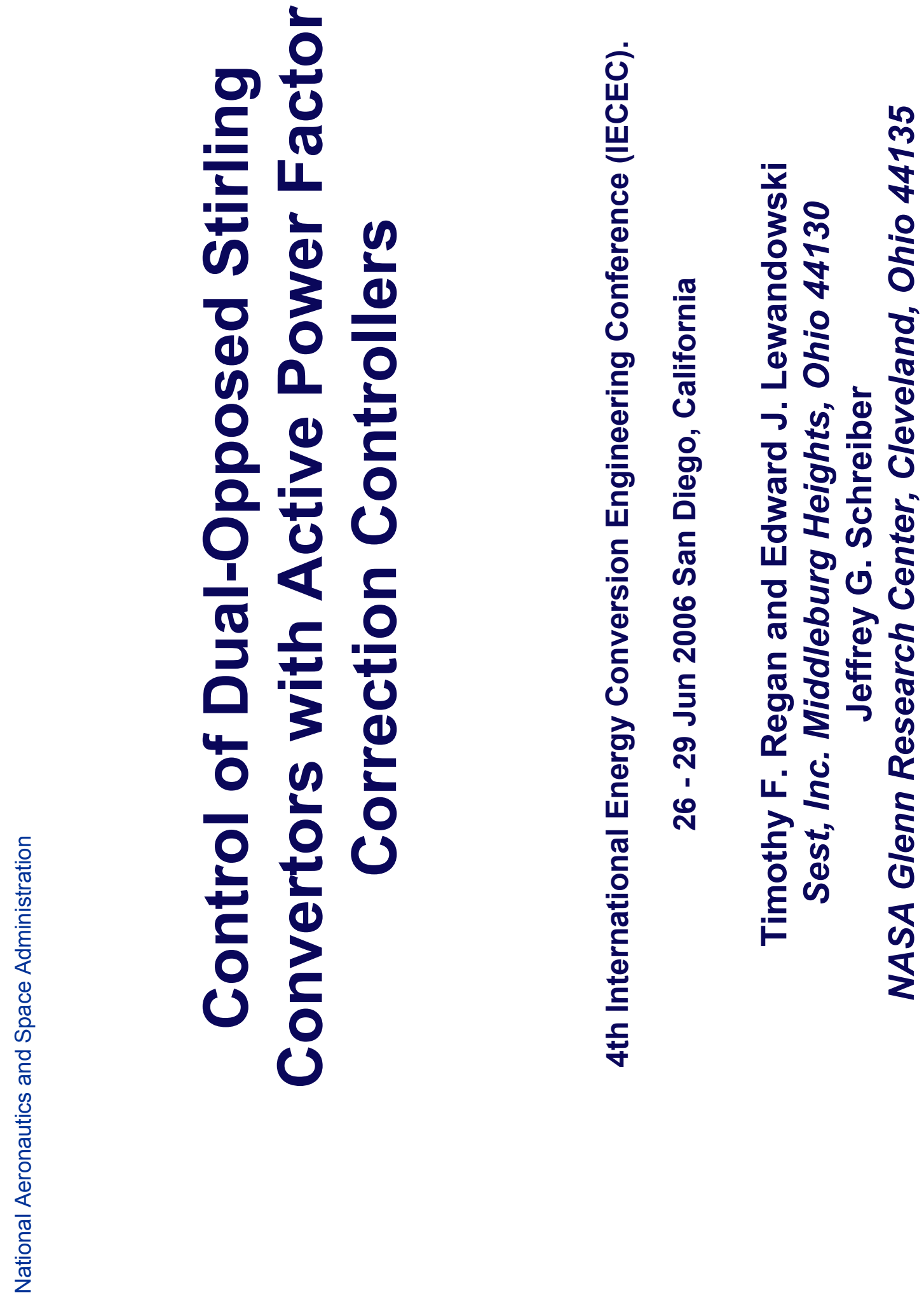

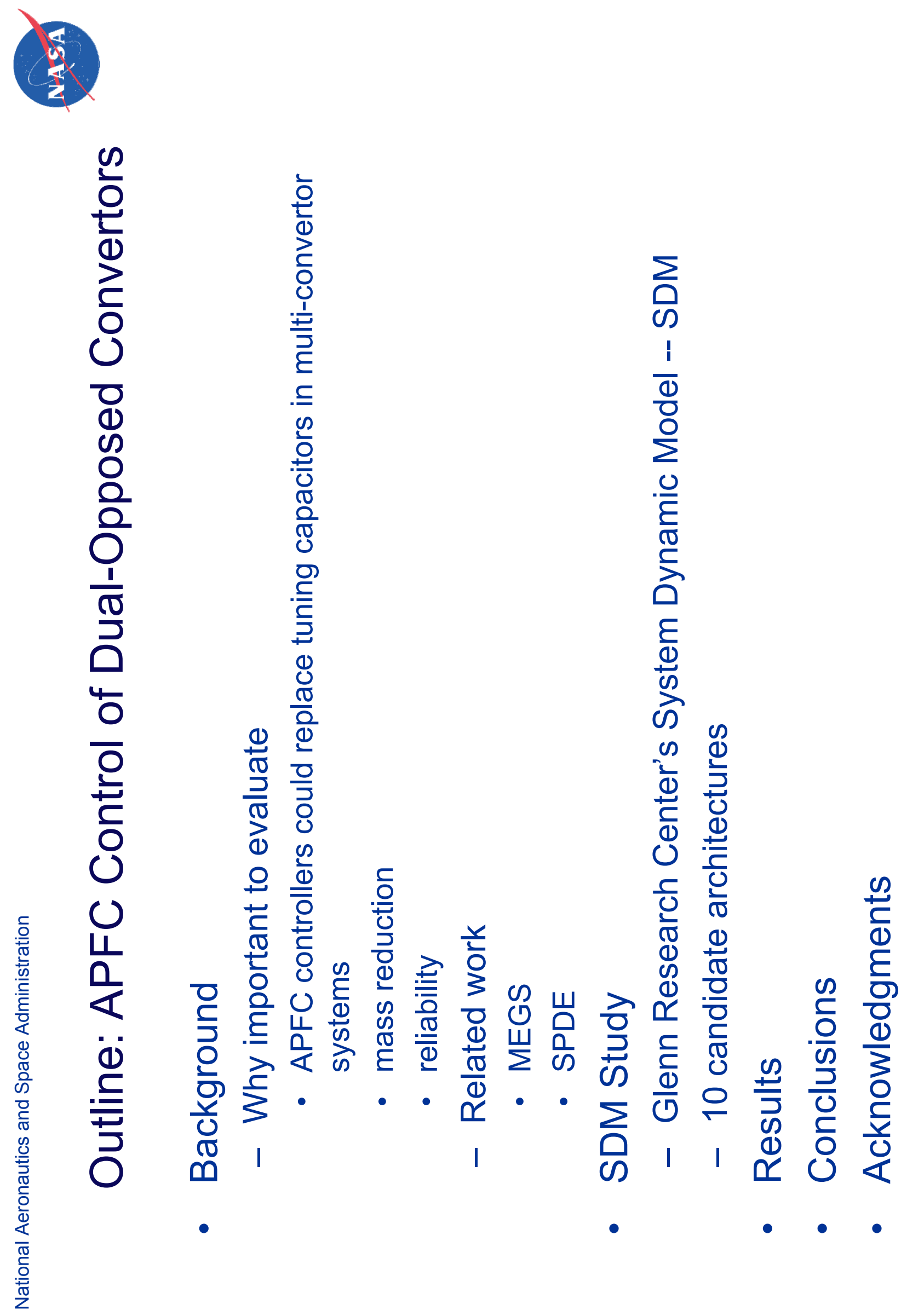

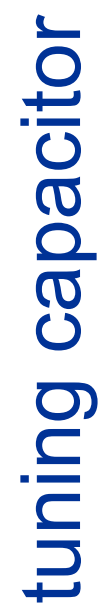

웅
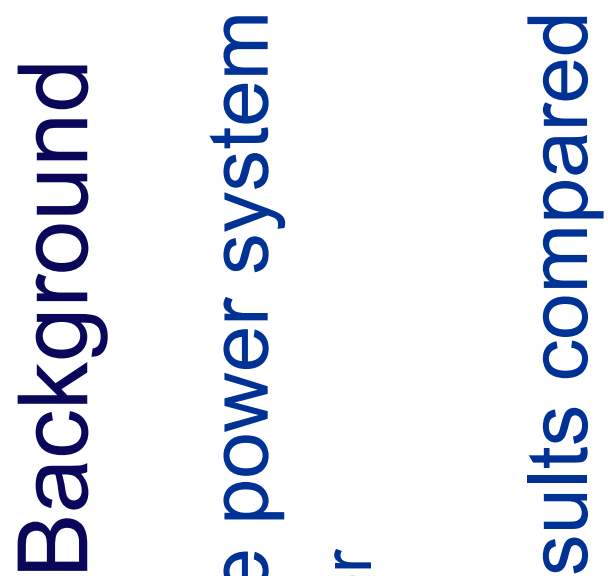

ป઼

으을 인

の

등 d

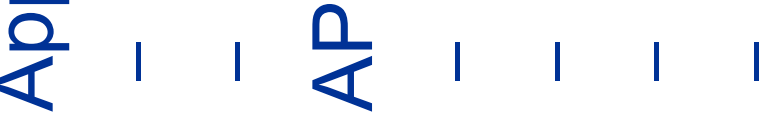




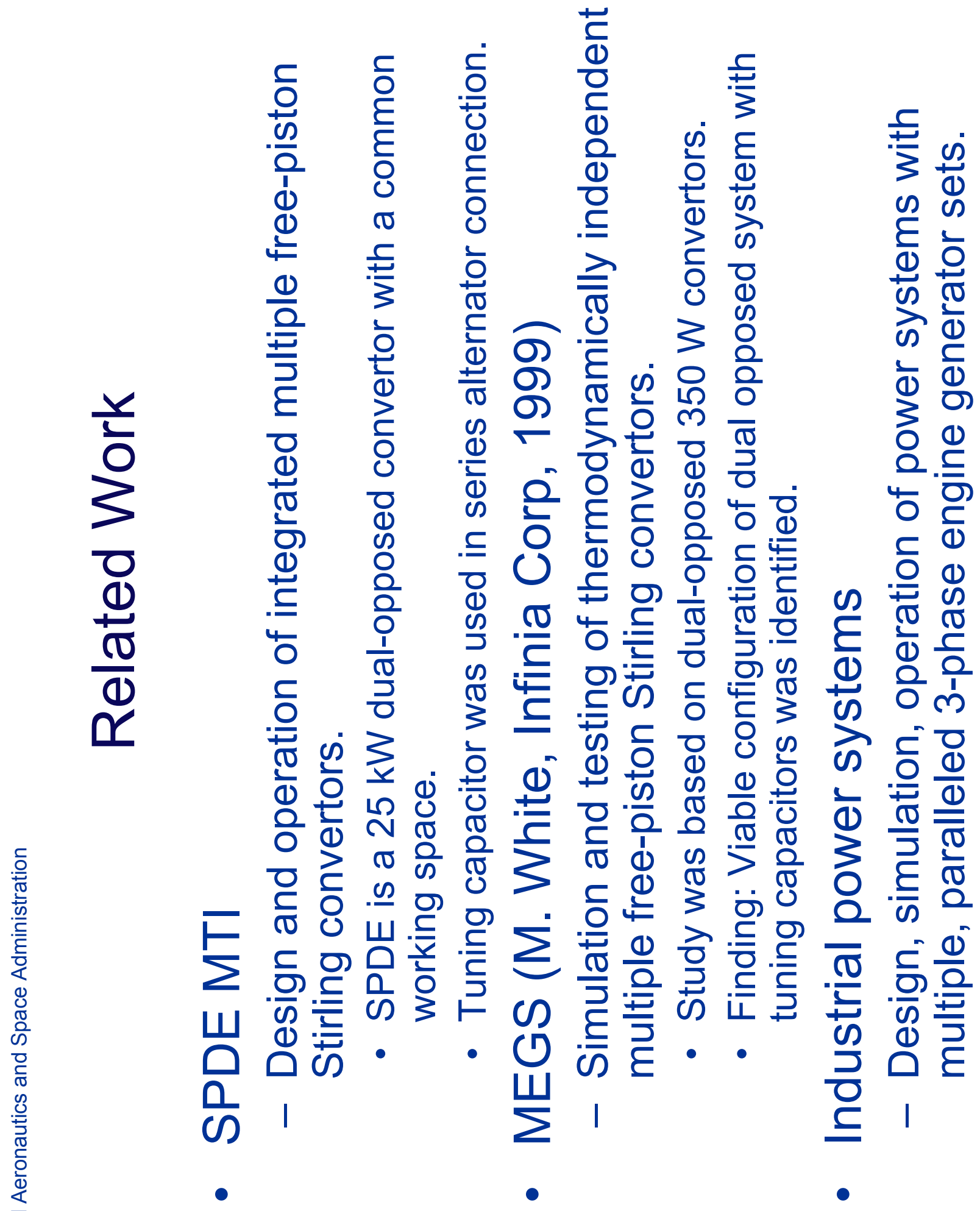



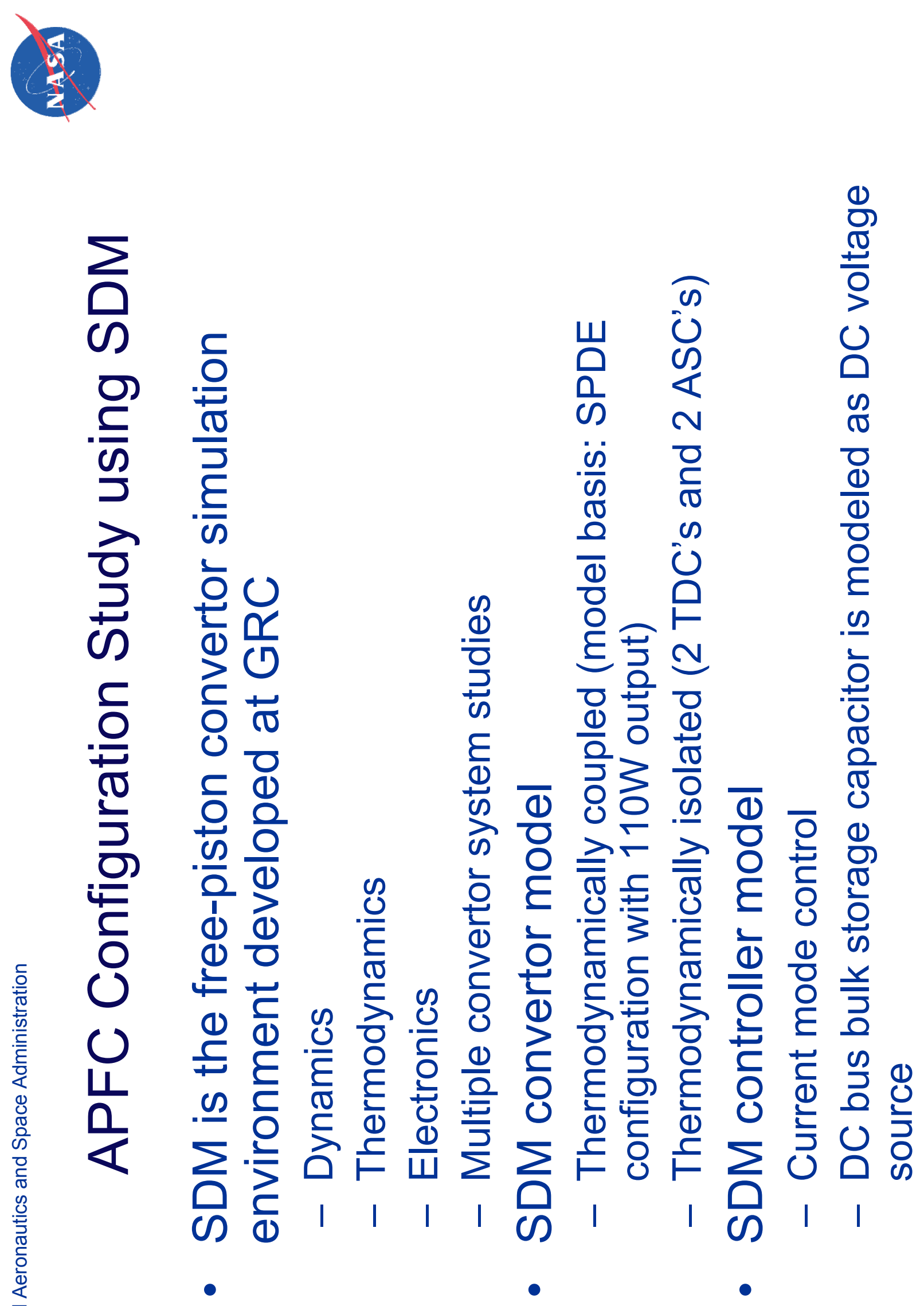

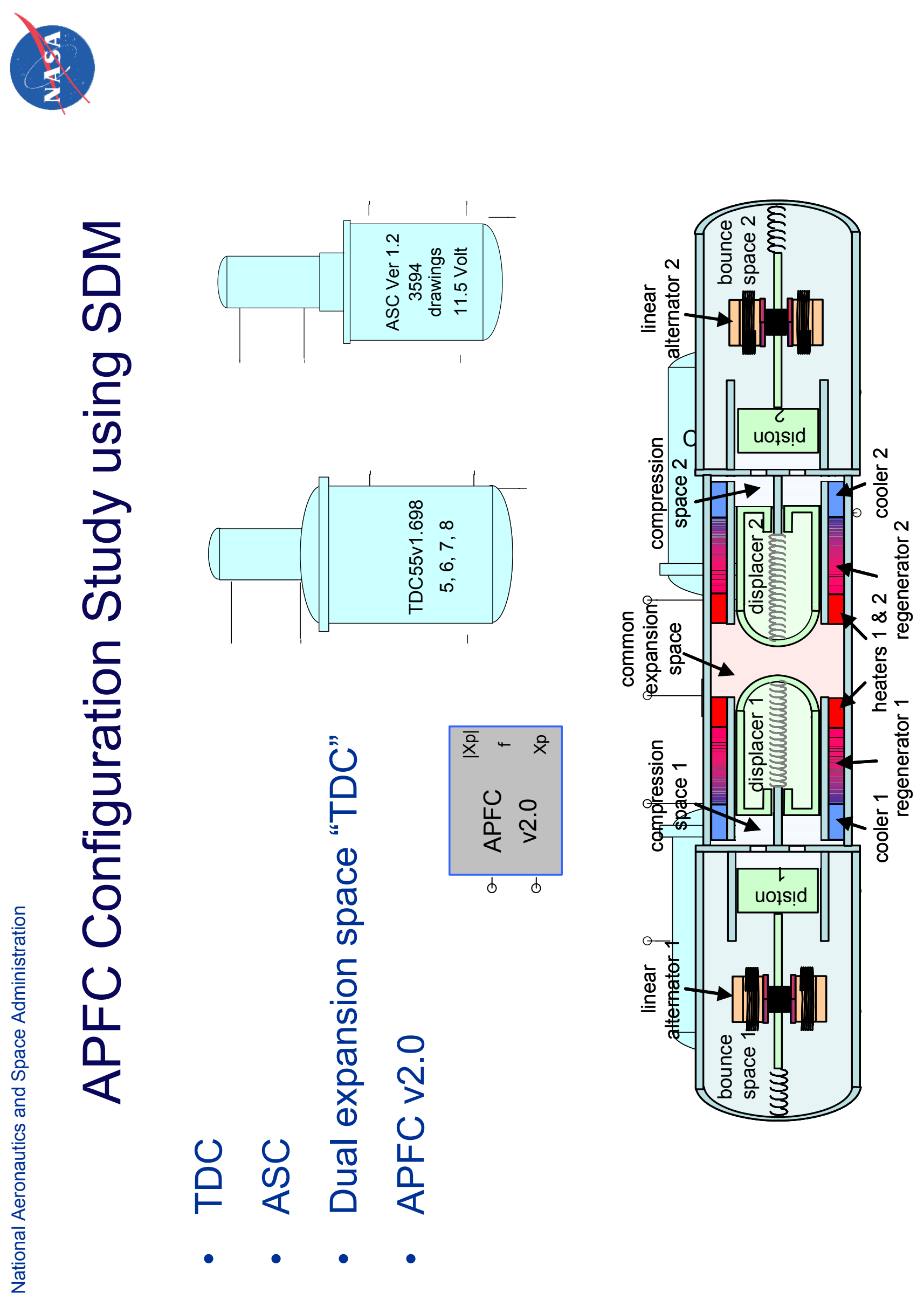


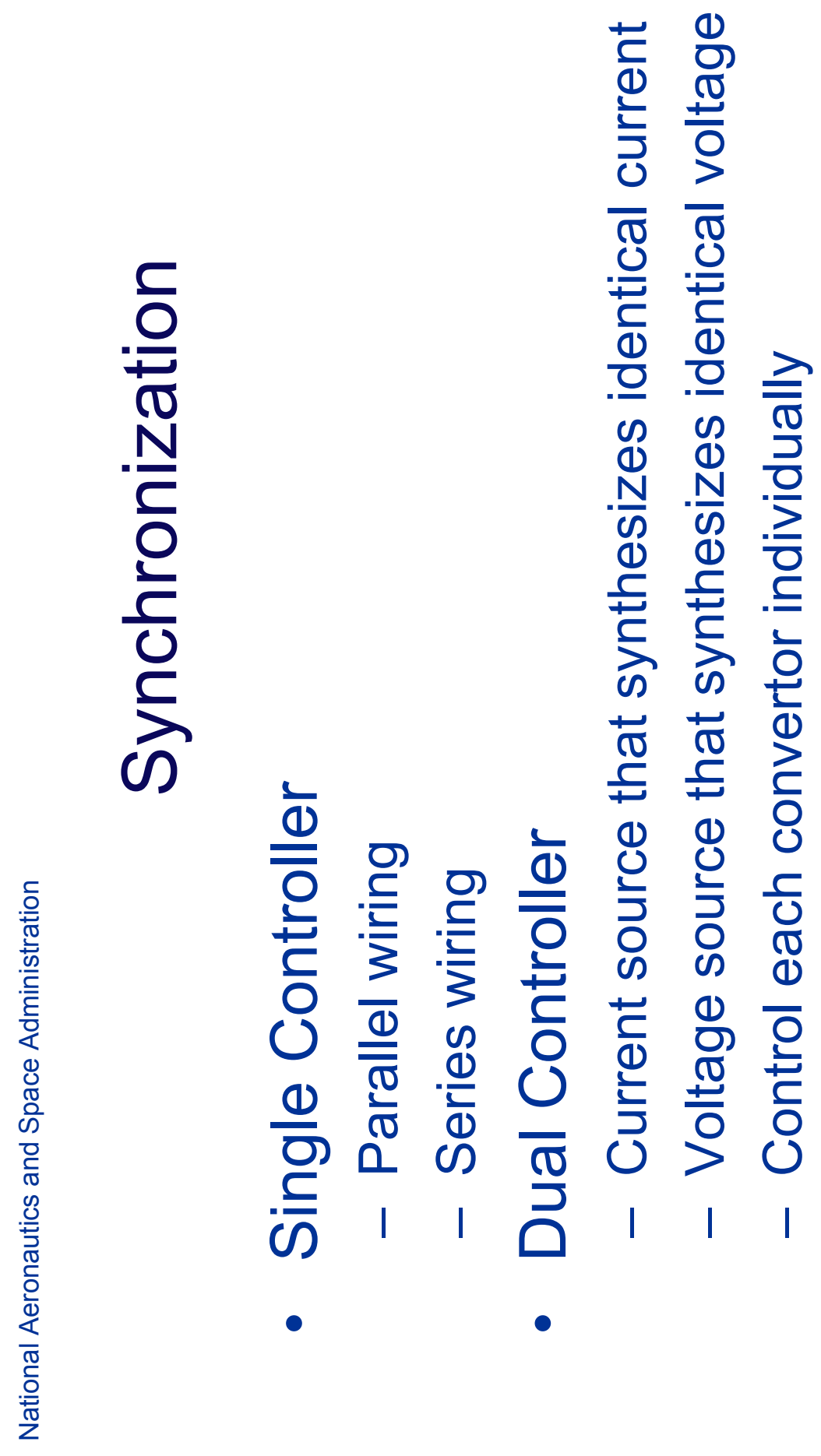



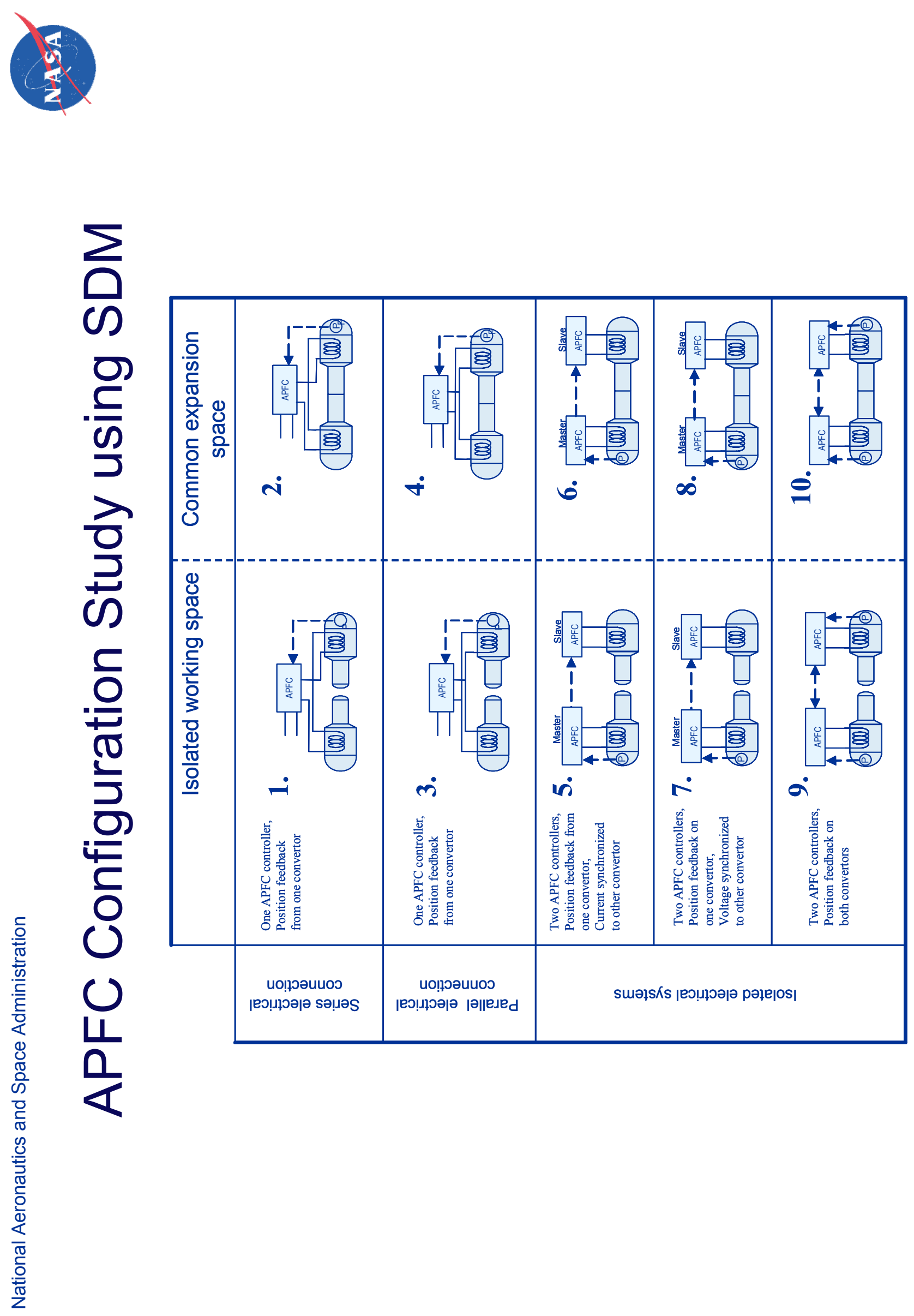


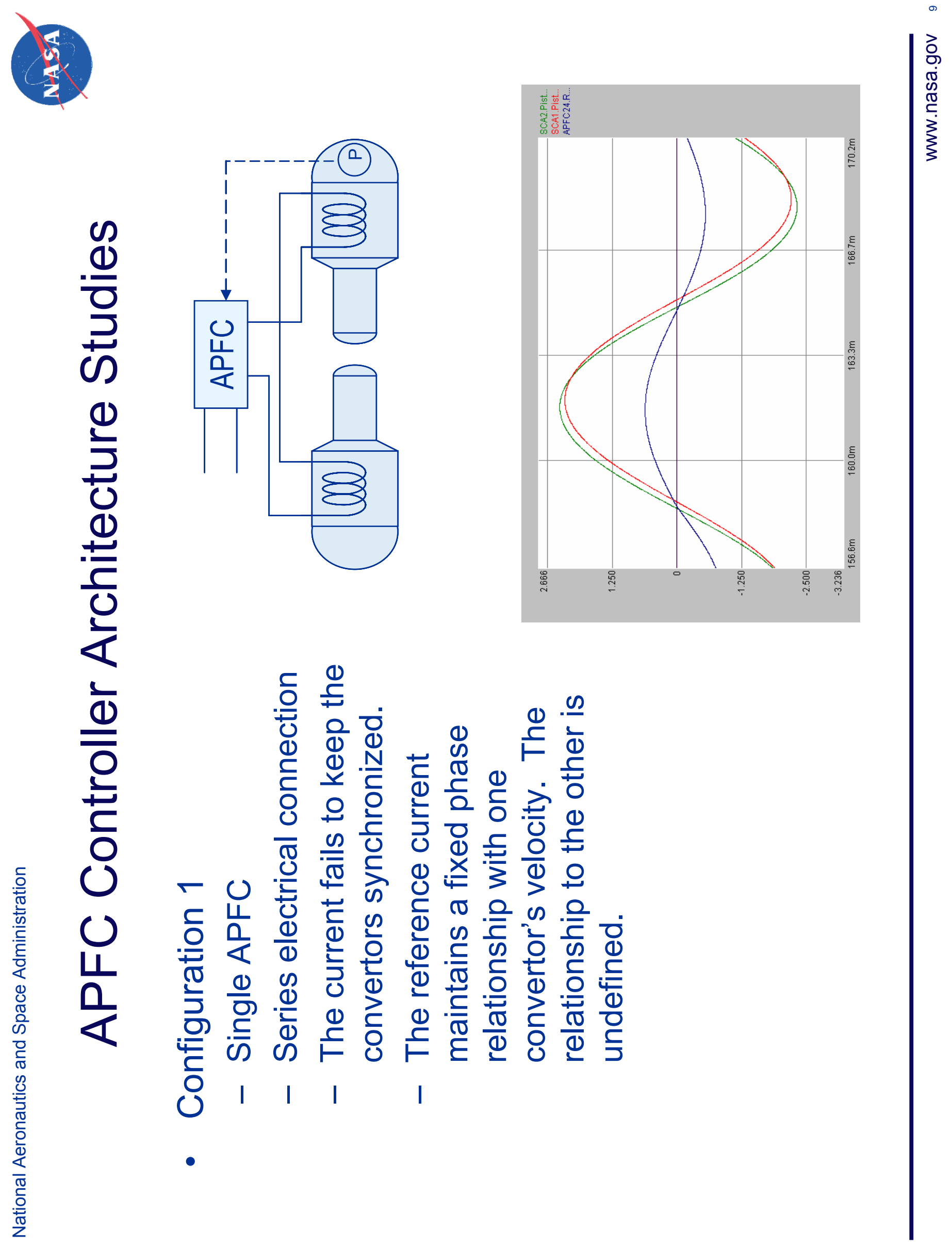




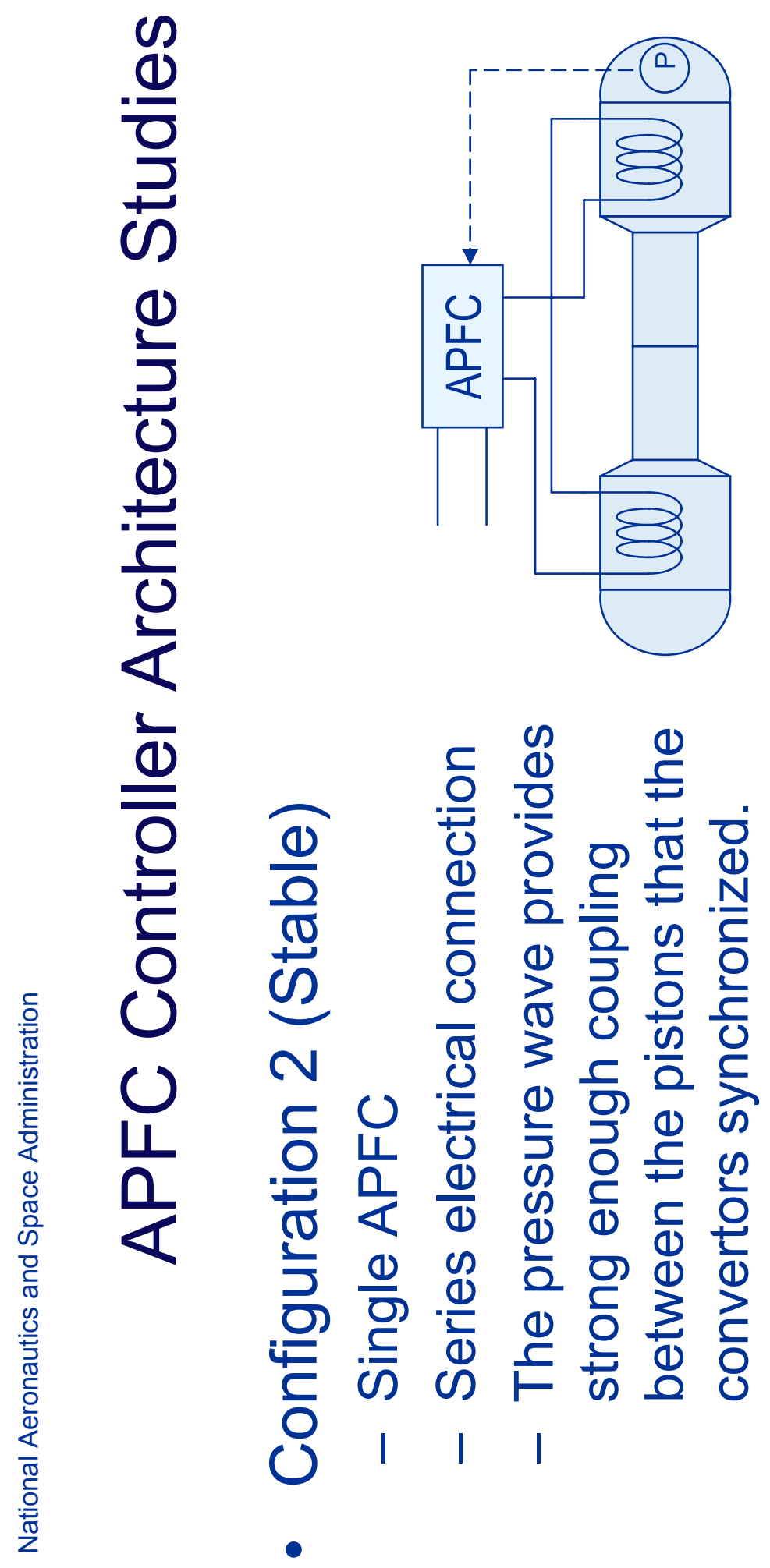




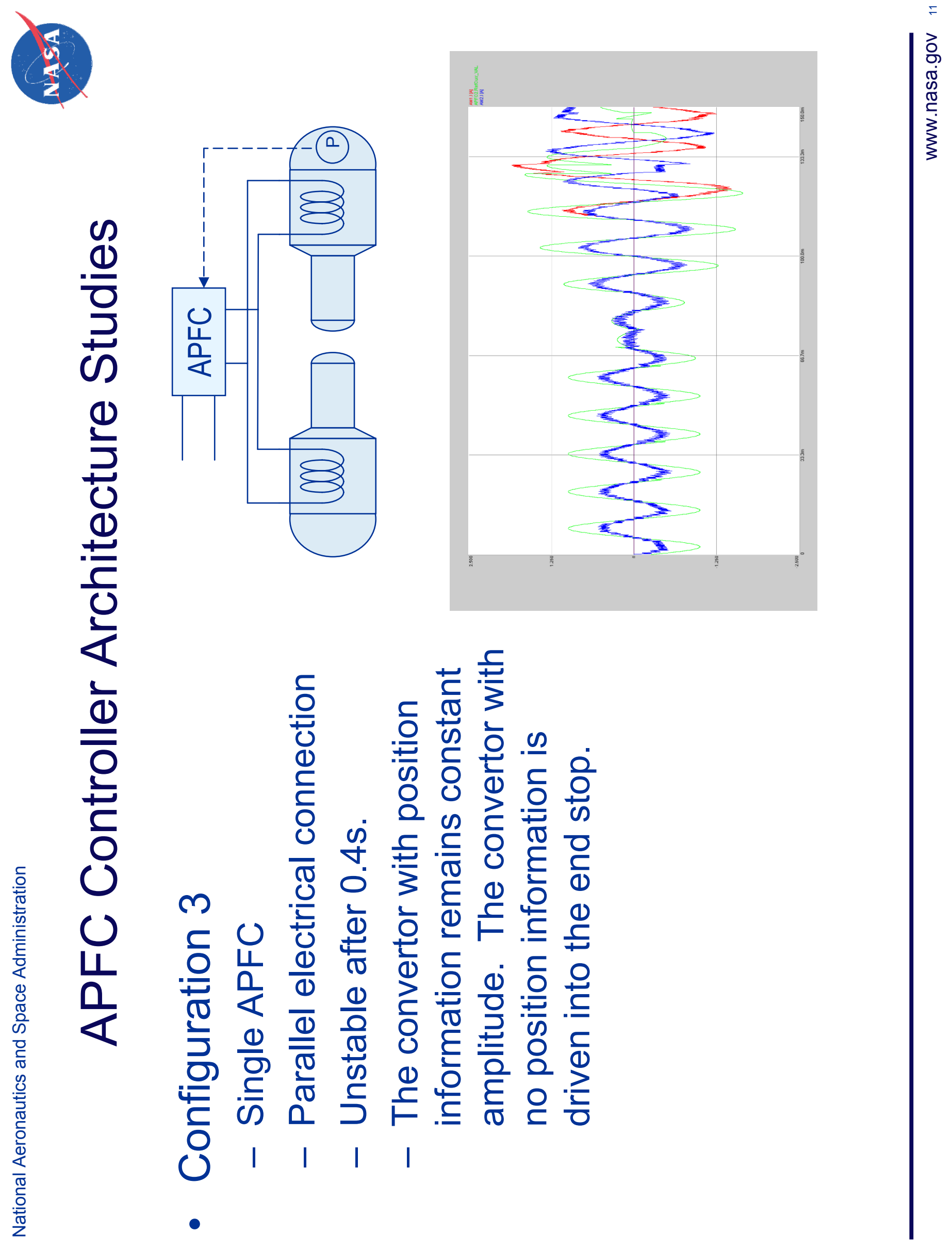




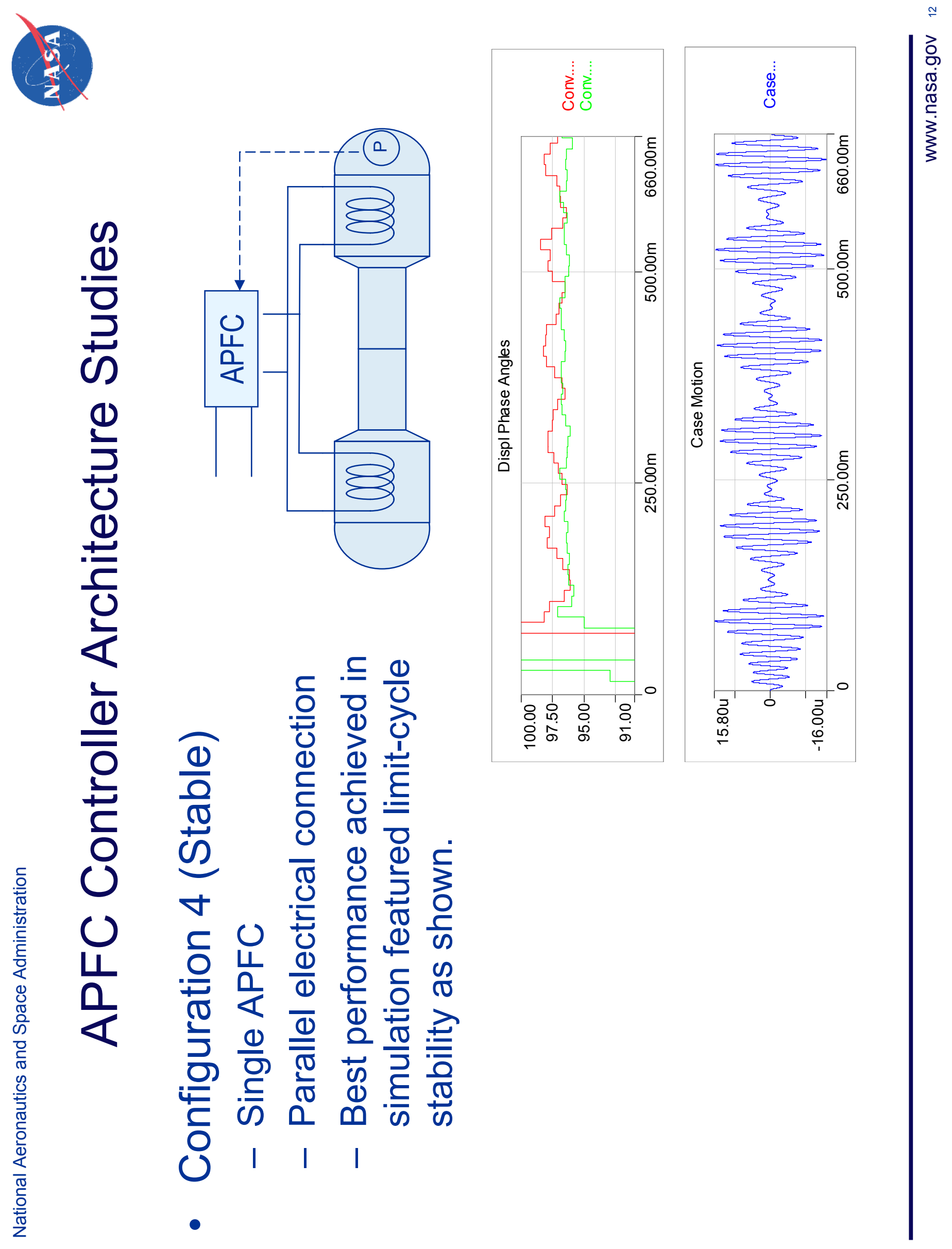




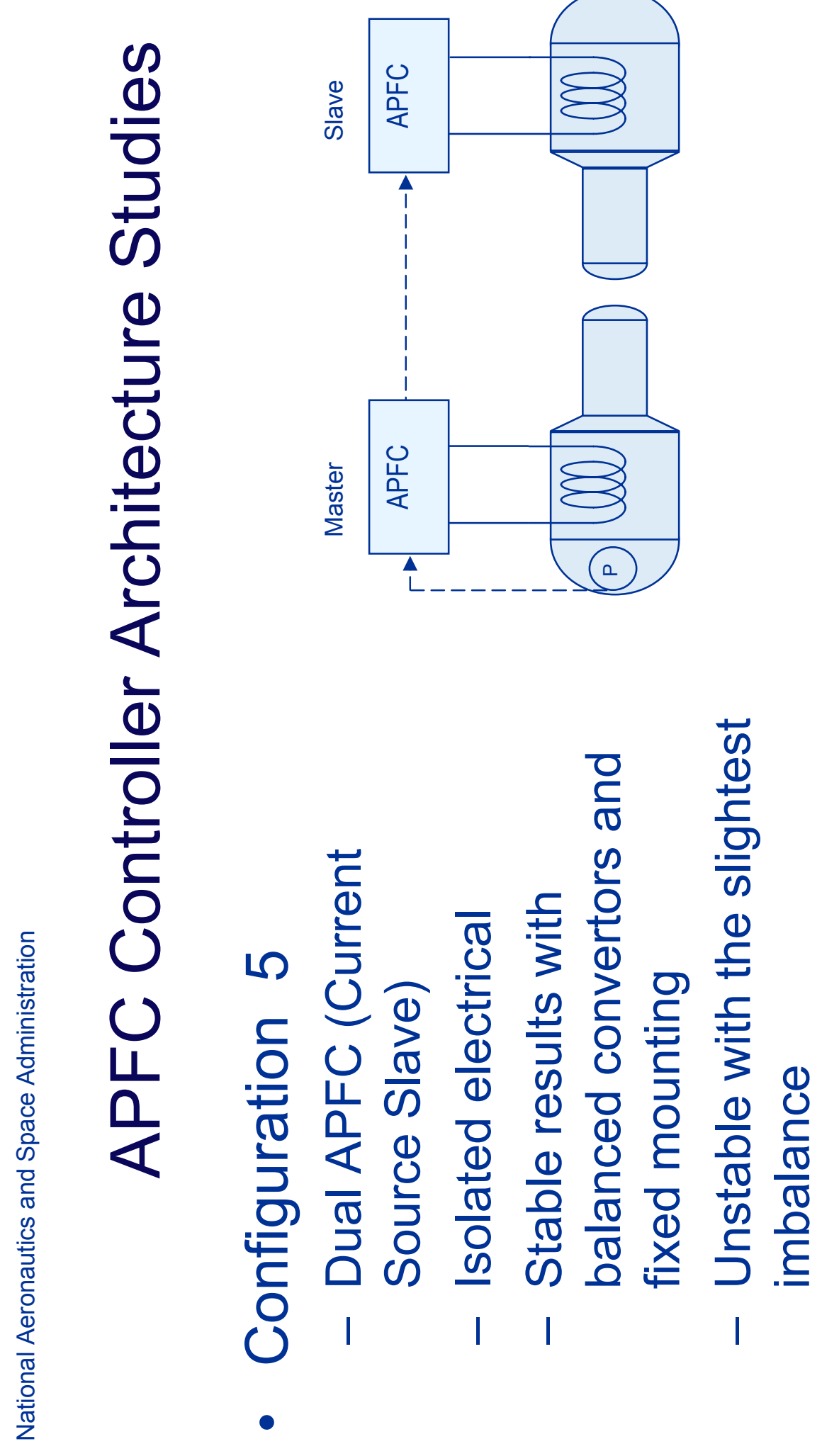




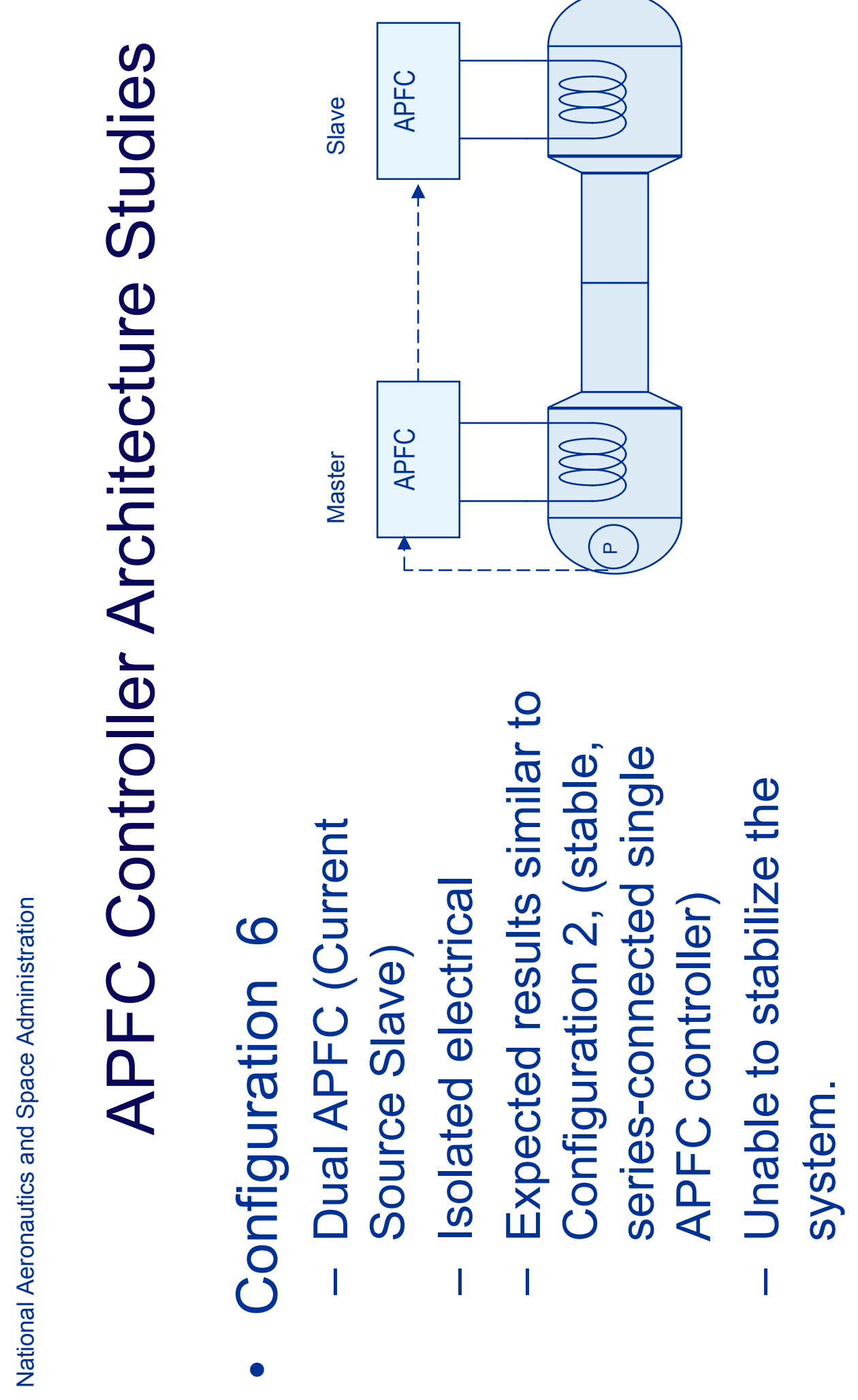




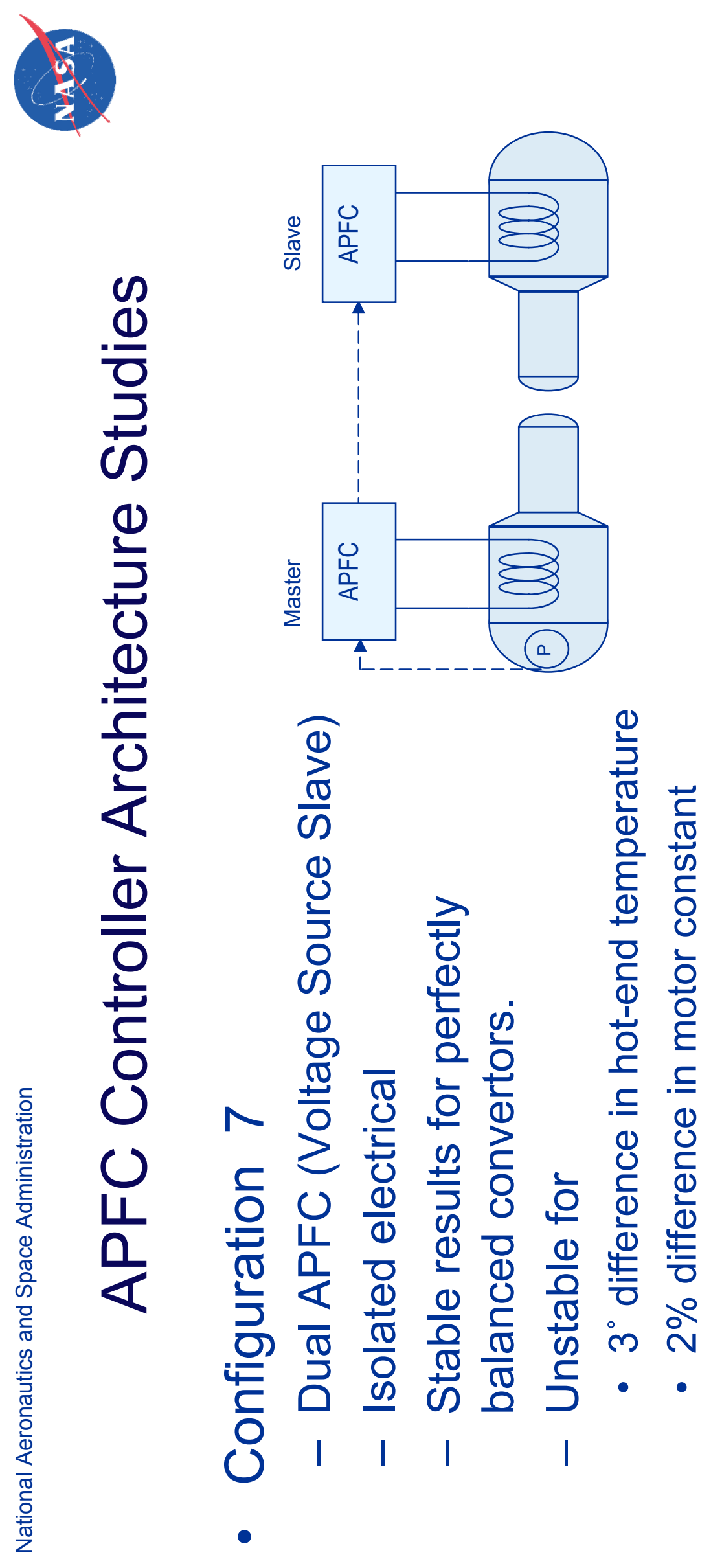




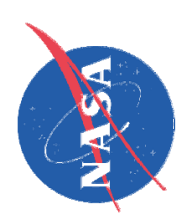

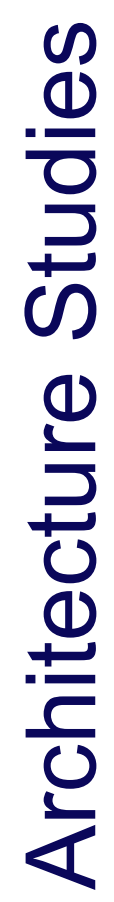
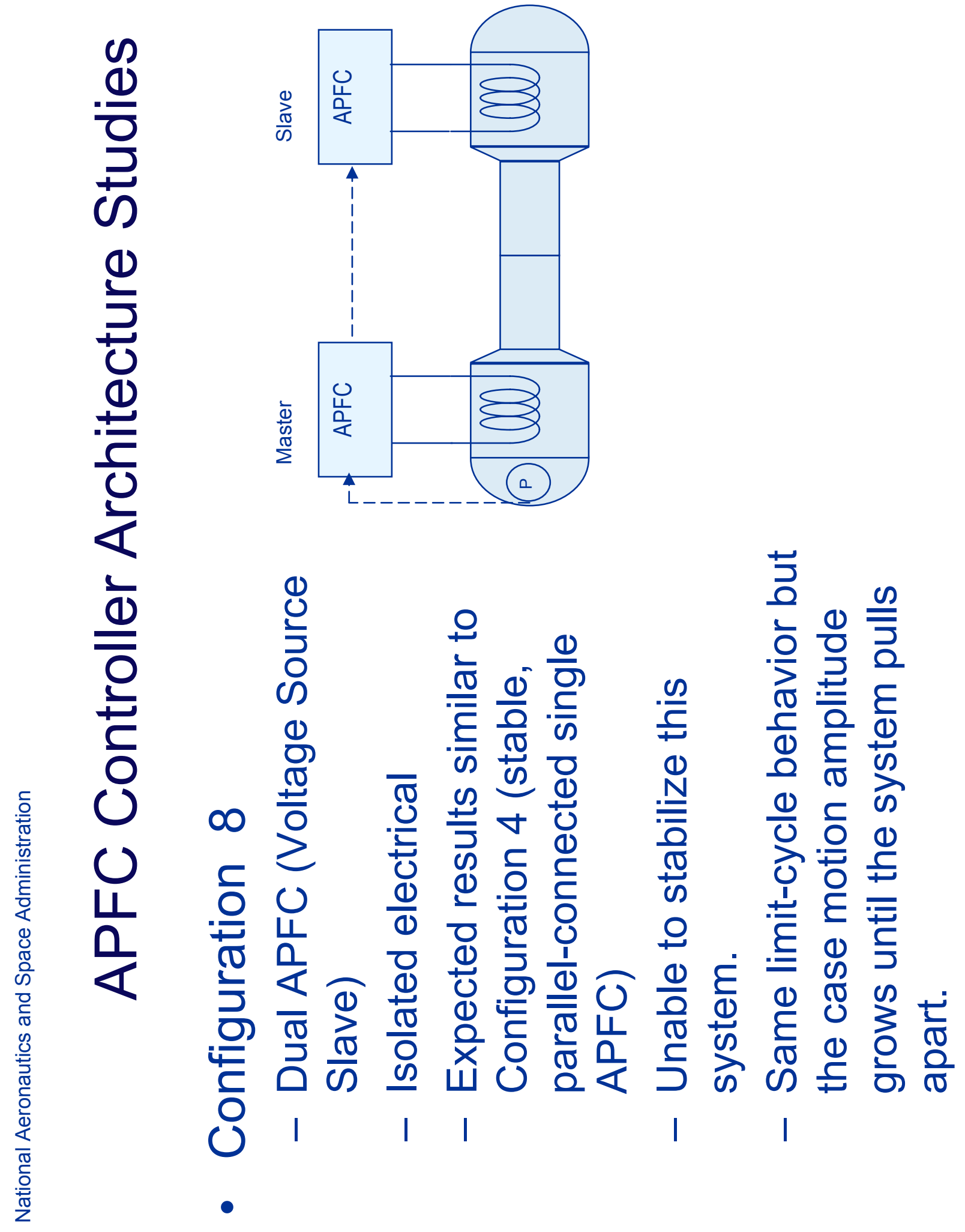
先

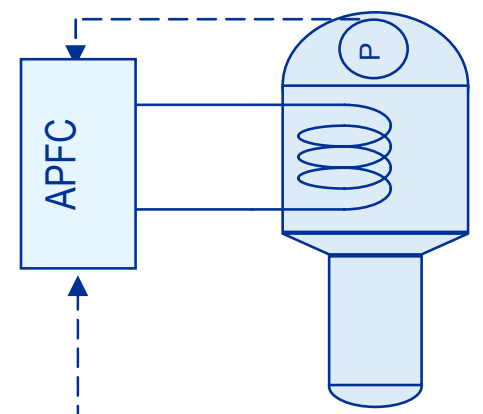

0
$\frac{1}{2}$
$\frac{1}{0}$
$\frac{1}{ \pm}$
$\frac{1}{0}$
$\frac{0}{4}$
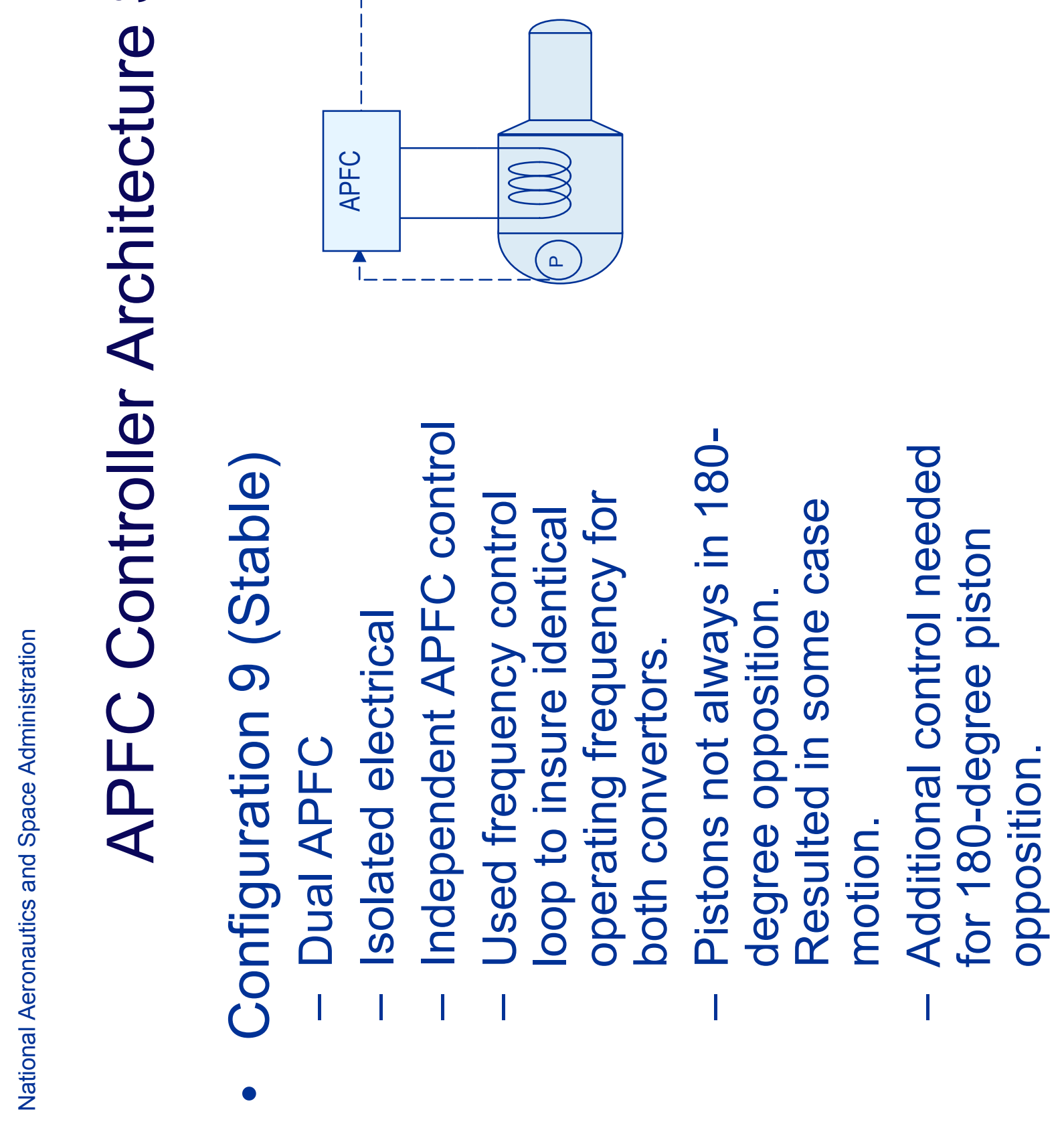


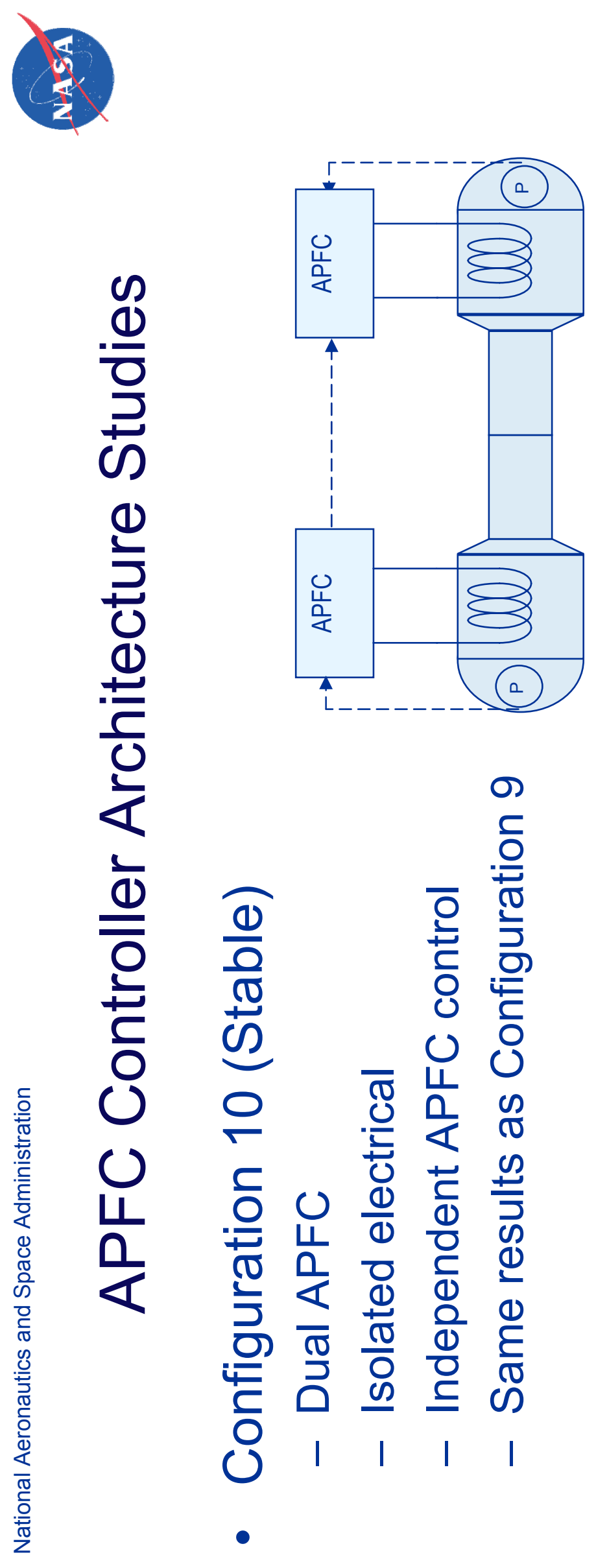




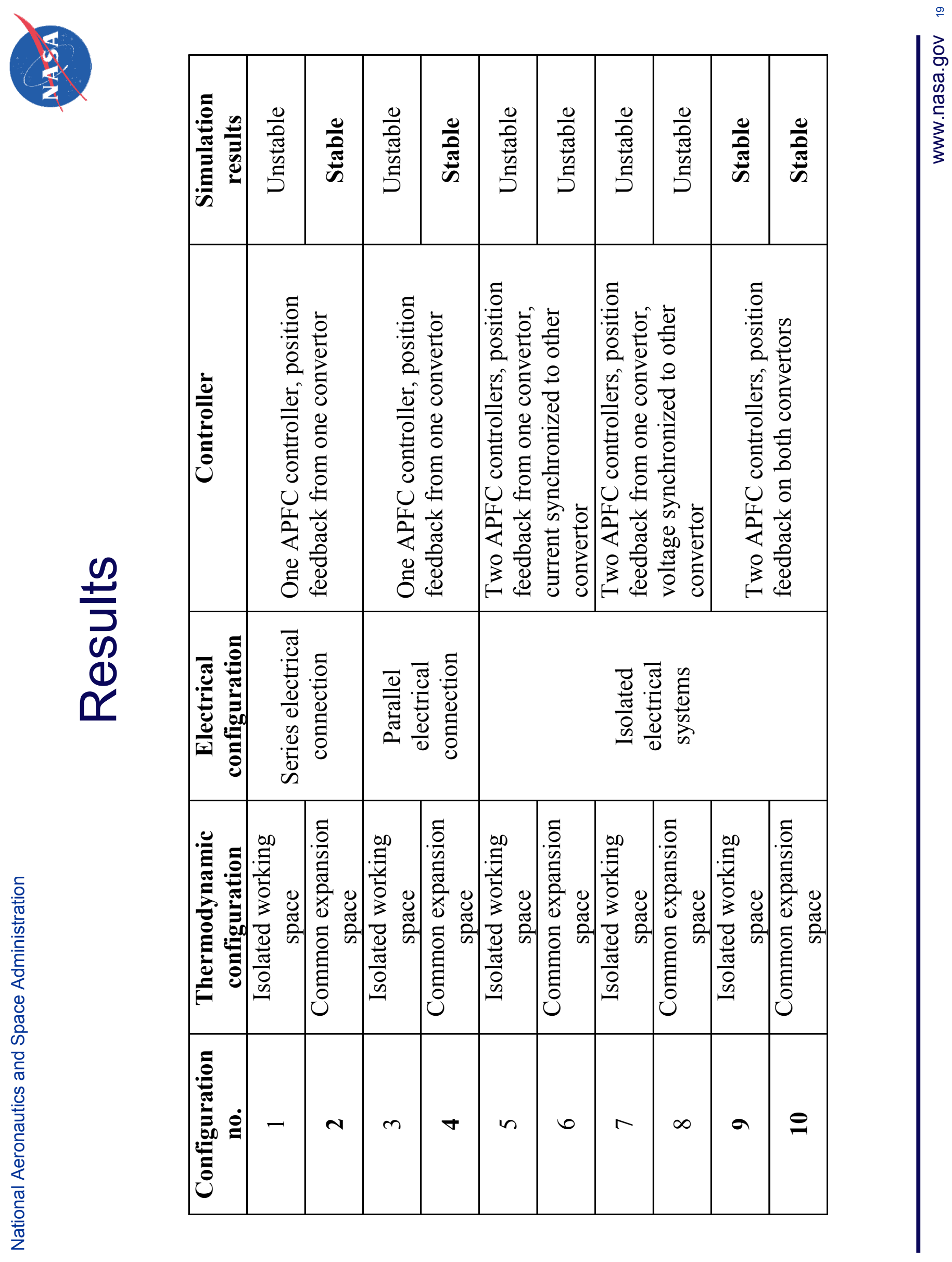




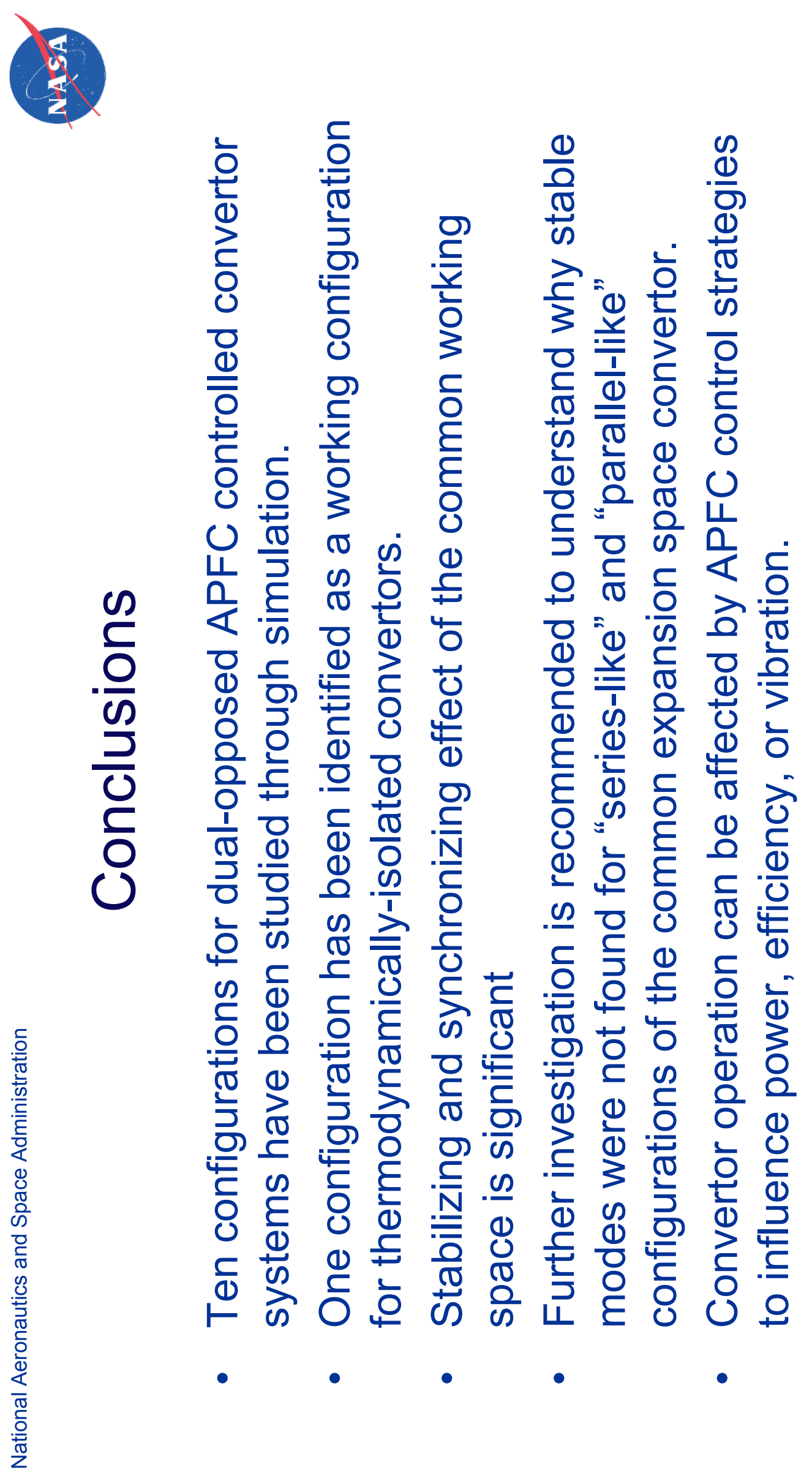




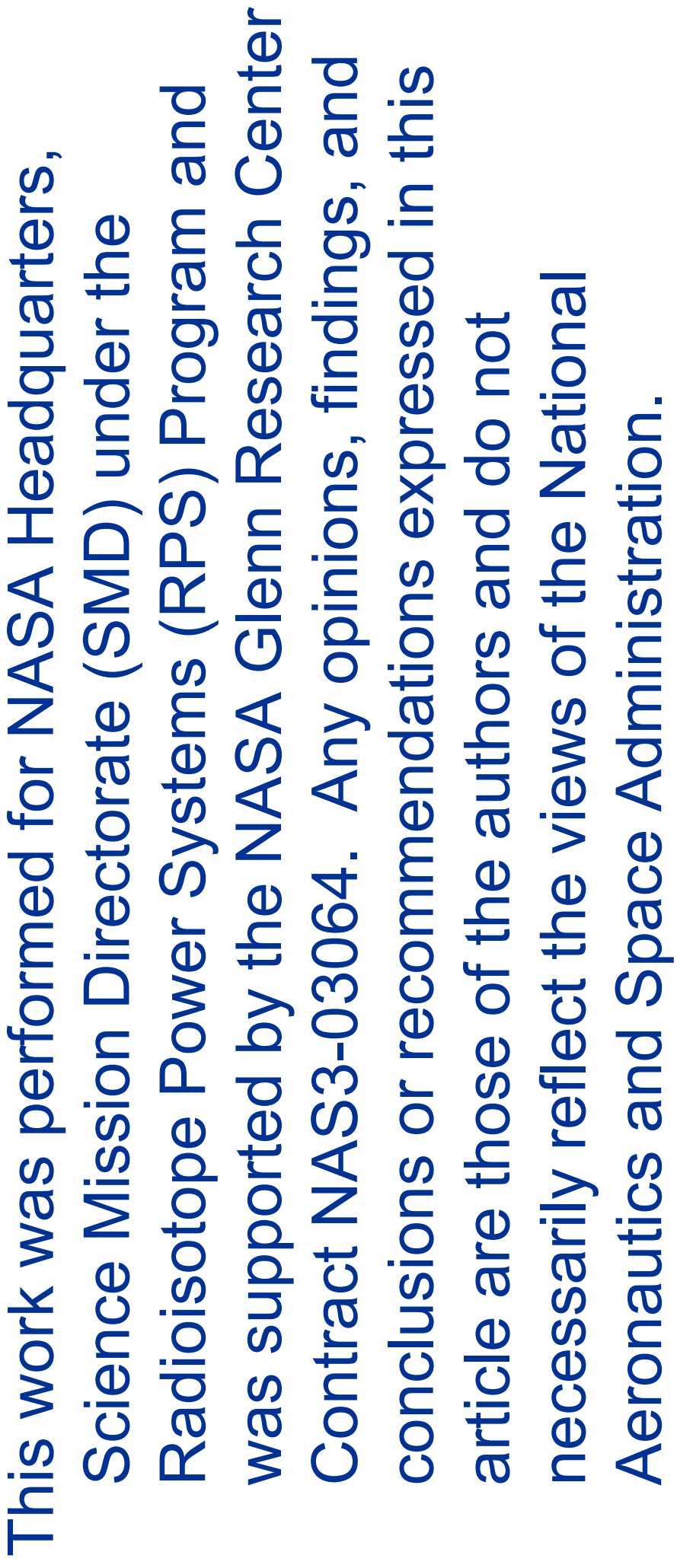

